\title{
TOWARDS A HUMAN ORIENTED SUSTAINABLE MIXED-USE DEVELOPMENT FOR INFORMAL AREAS WITHIN CITIES' CENTERS CASE STUDY: THE REDEVELOPMENT PROJECTS OF (DHARAVI, MUMBAI AND MASPERO, CAIRO.)
}

\author{
*Mohsen Mosaad Abd El Fatah Anbr, Ibrahim Rizk Hegazy and Mohamed M.Elazab \\ Architecture Department, Faculty of Eng., Mansoura University, Mansoura, Cairo, Egypt. \\ *Corresponding author E-mail: Mohsen_anbr@hotmail.com
}

\begin{abstract}
Many historical and ancient cities witness the spread of informal areas (slums) near the centers of these cities, which are urban areas with high investment value. The development of most of these areas is hampered for several reasons, including the difficulty of dealing with landowners and residents living in these areas and the interests of investors and real estate developers conflict with residents continuity after development, which often leads to residents displacement. The research presents a comparative analytical study of the development projects of two important informal areas each with a distinct strategic location and a review of multiple development attempts over the past 50 years (Daharavi, Mumbai and Maspero Triangle,Cairo).Through this, the research aims to reach an investment mechanism that stimulates investors and real estate developers to participate in the development of making human first, and preserves the residents of these informal areas and ensures their right to continue in their areas after development. The recommendations can be taken into account in the redevelopment of similar areas
\end{abstract}

Key Words: Real Estate Investment, Sustainable Development, Mixed-Use Development, Informal Settlements, Social Justice

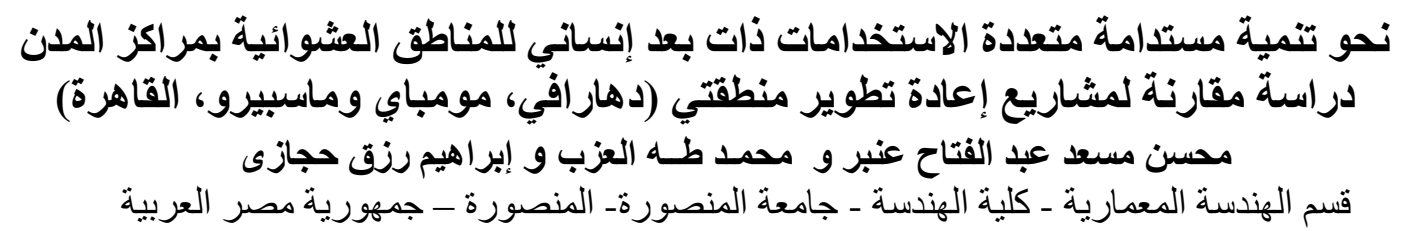




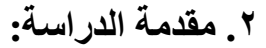

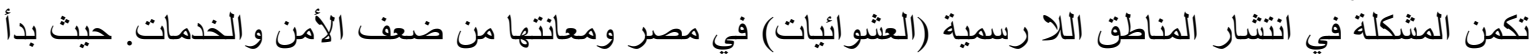

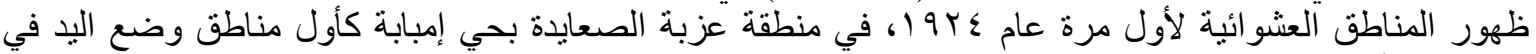

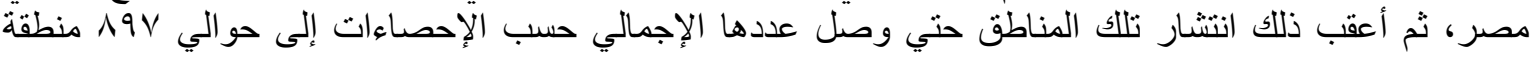
كالتاللي: معنر

\begin{tabular}{|c|c|c|c|}
\hline & النسبة & المساحة & العشو ائيات \\
\hline ة العمر انية لمدن الجمهورية & ( & ^. • 1 ا ألف فدان & مساحة المناطق العشو ائية في مصر \\
\hline لي مســاحـة المناطق العشو ائية & \% \% \% & r. 107 ألف فدان & مساحة المناطق العشو ائية غير المخططة \\
\hline ن الجمهورية (ع Y مدينة) & (97.7 97 \% مز & & تنتشر المناطق العشو ائية في YY F مدينة \\
\hline ي مساحة المناطق العشو ائية & 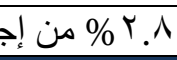 & 0. ــ ألف فـدان & مساحة المناطق العشو ائية غير الآمنة \\
\hline إلمساحة & النسبة للعدد & عدد المناطق & المناطق العشو ائية غير الآمنـة (ع درجات) \\
\hline r. r ألف فدان & $\% \vee 1.0$ & ا & المناطق ذات درجــة الخطورة الثنانية \\
\hline 1. ألف فدان & $\% 17 . \wedge$ & 99 منطقة & المناطق ذات درجـة الخطـورة الثــالثة \\
\hline r. ألف فدان & $\% \backslash 1 . \mathrm{V}$ & إ منطقــة & المناطق ذات درجني الخطورة الأولى والر ابعة \\
\hline مــ ألف فـدان & $\% 1 \cdots$ & 101 منطقة & \multirow{2}{*}{ الإجمالي } \\
\hline \multicolumn{3}{|c|}{ ؟. 0 اب ألف وحدة سكنية على مستوى الجمهورية } & \\
\hline
\end{tabular}

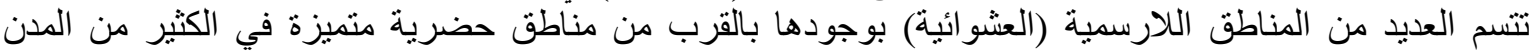

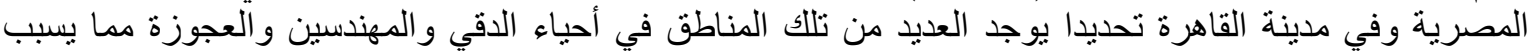
تشويه الصورة البصرية لتلك المناطق وهي مناطق ذات قيمة استثمارية عالية وينبخي تطوير ها، ولكن ينتثر تطوير أغلب تللك المناطق لعدة أسباب منها:

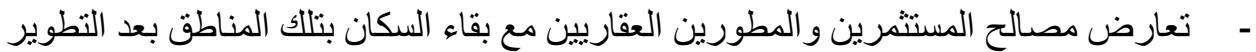

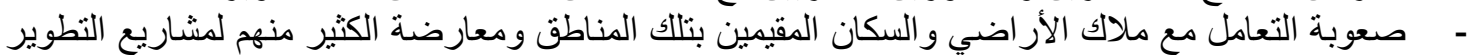

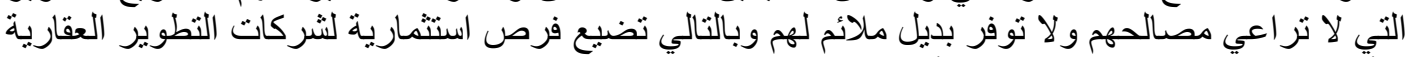

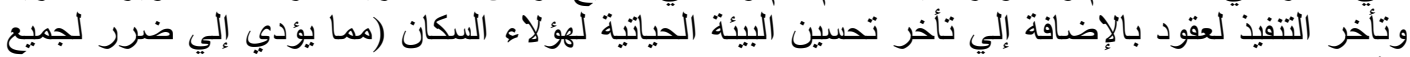

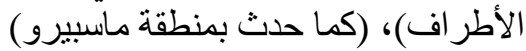

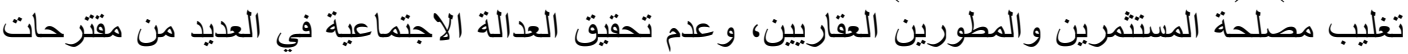

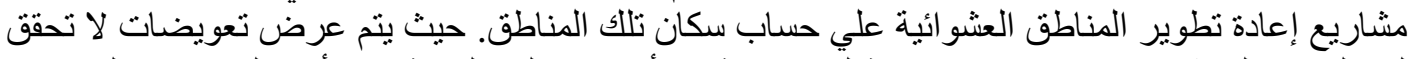

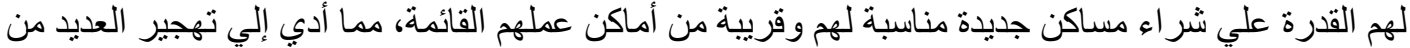

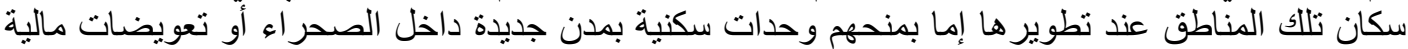
غير مناسبة عدم وجود آلية واضحة تحفز وتشجع تطوير واستثمار المناطق العشو ائية، بحيث تحقق المصلحة وتحدد العلاقة بين جميع أطر اف أصحاب المصلحة (الصغة (Stakeholders) : (السكان المقيمين بالمنطقة. المطورون و المستثمرون- الدولة)
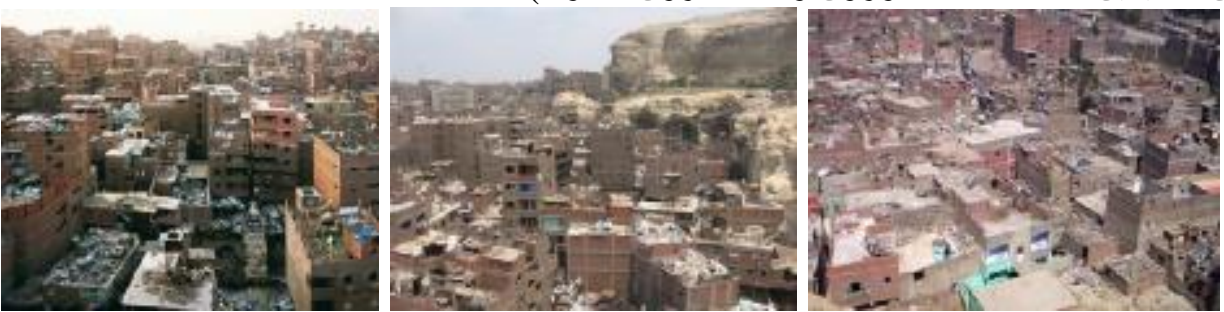

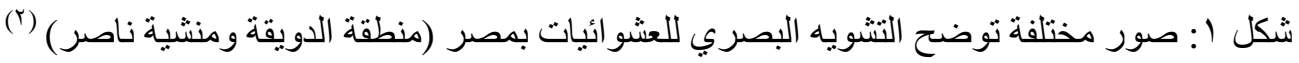

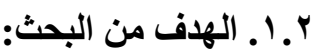
يهدف البحث إلى در اسة مشاكل التطوير العمر اني للمناطق العشو ائية ذات القيمة الاستثمارية ومحاولة إيجاد صيغة الإنة تحقق العائد الاستثماري مع الحفاظ على سكان تللك المناطق وتضمن حقهم في الاستمر ار في مناطقهم بعد تطوير ها لإنا و عدم تهجير هم أو إخلاء مناز لهم قسريا منها 


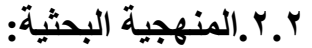

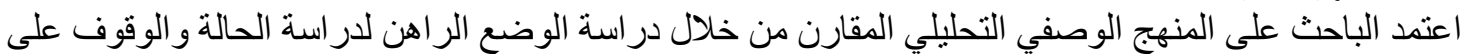

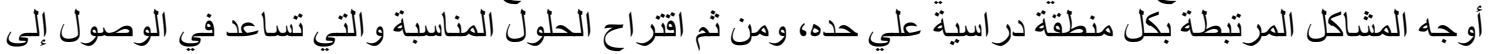

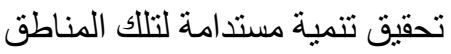
r. الأسباب العمرانية والاقتصادية والاجتماعية والسياسية والتشريعية لظهور العشوائيات بالمدن:

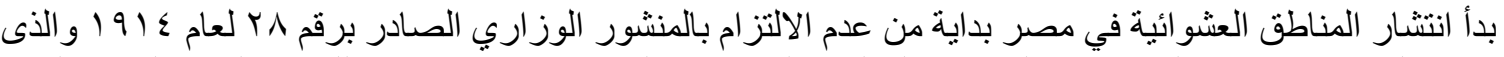

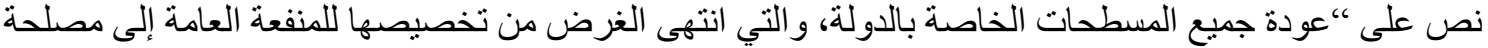
الأملاك الأميرية" وأدت الأسباب الآتية إلي زيادة انتشار ها.

\begin{tabular}{|c|c|c|}
\hline 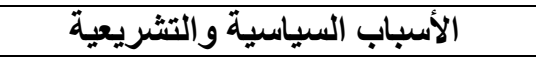 & الأسباب الاجتماعية & 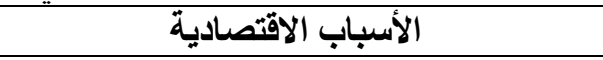 \\
\hline ل المتابعة & ف ف المشار كة المجتمعي & 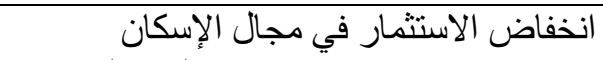 \\
\hline وتغاضي المحليات = & 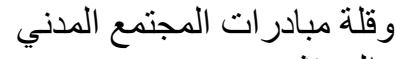 & 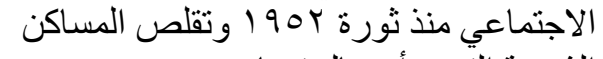 \\
\hline و الامتداد العشو ائي : & و المستثرين & 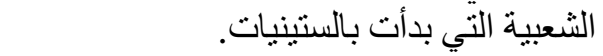 \\
\hline نظم التمليك المتبع مذ & \multirow{4}{*}{ 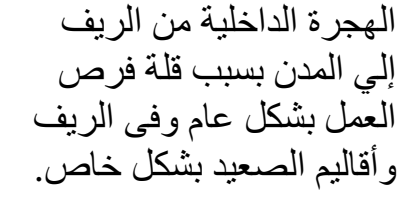 } & \multirow{4}{*}{ 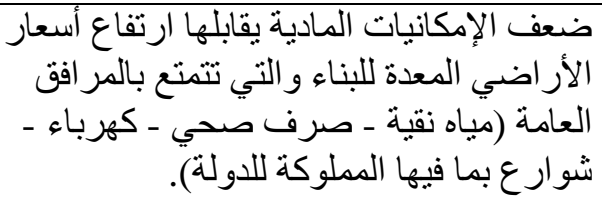 } \\
\hline القرن الماضي صعبد & & \\
\hline المسكن للمو اطن م & & \\
\hline & & \\
\hline الأحد & \multirow{2}{*}{ زيادة الجريمة بالعشو الئيات في } & \multirow{2}{*}{ زيادة القيمة الإيجارية أسعار مو اللبناء و المساكن وضن من الإسكان } \\
\hline 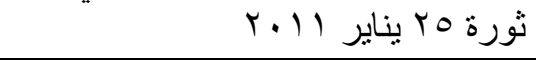 & & \\
\hline اعتبار التجمعات ال الت الت ال & \multirow{5}{*}{ 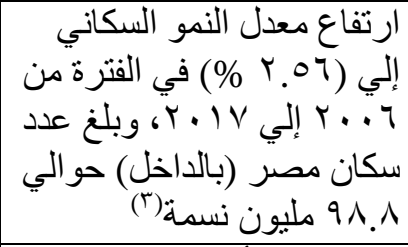 } & \multirow{4}{*}{ 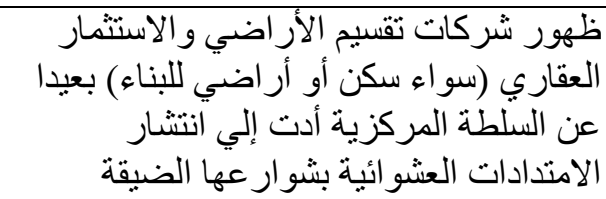 } \\
\hline ق ق قبل عام & & \\
\hline شجع وساعد على ذ & & \\
\hline 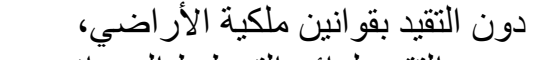 & & \\
\hline ودون التقيد بلو ائح & & انخفاض مستو ي دخل المناطق العشو ائية \\
\hline 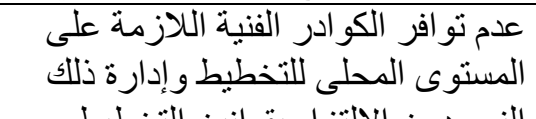 & \multirow[t]{6}{*}{ كبر حجم الأسر النسبي } & 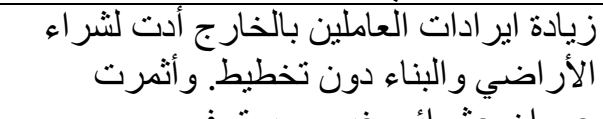 \\
\hline النمو دون الالتز ام بق & & عمر ان عشو ائي غير مسبوق في مصر \\
\hline تحديد القيمة الإيجارية & & تمركز الخدمات في المدن الرئيسية واتصلال \\
\hline وف القطاع & & الكثير من المناطق العشو ائية بمر اكز المدن \\
\hline ي الدخل و الاتجاه إلي الإسكان & & الدخل علي التوطن بتلك المناطق مما شجع محدودي \\
\hline 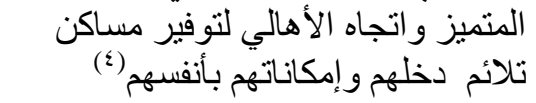 & & عدد الوحدات السكنية المغلقة و الغير مستغلة \\
\hline
\end{tabular}
جلول r ب الأسباب العمرانية والاقتصادية والاجتماعية و السياسية والتشريعية لظهور العثوائيات

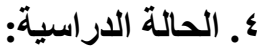

نم تحديد منطقتين در اسيتين هامتنين لتطوير المناطق العشو ائية، روعي عند اختيار هما أن تكون ظروفهرا متشتابهة، فكلا

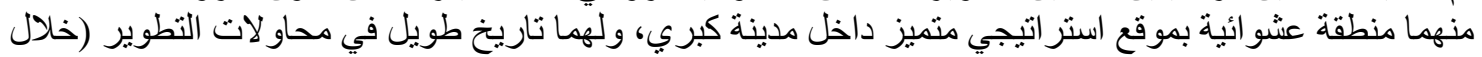

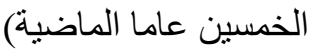
أـ المنطقة الدر اسية الأولي: (منطقة دهار افي، مدينة مومباي، الهند) ذاتئة ذات الموقع الاستر اتيجي

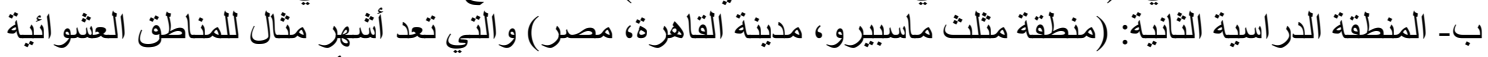

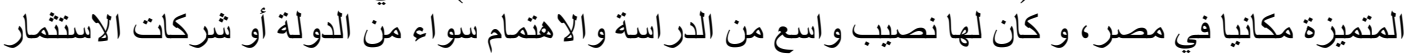
و التطوير العقاري أو الدر اسات الأكاديمية.

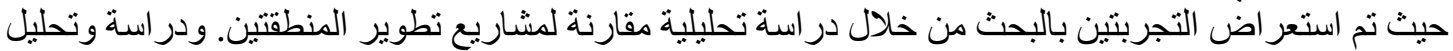

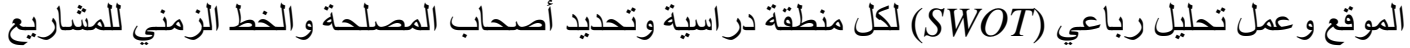

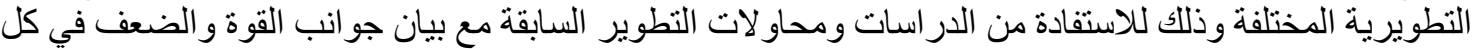

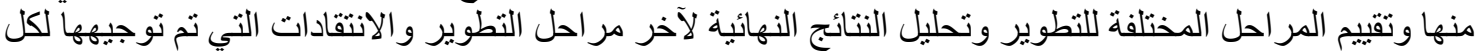

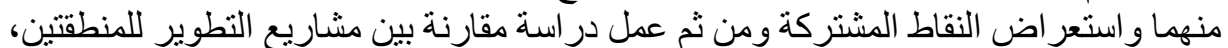

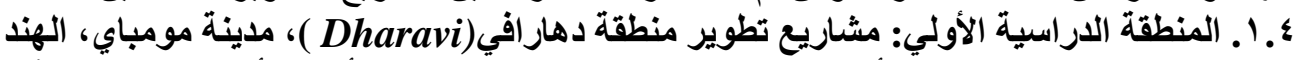

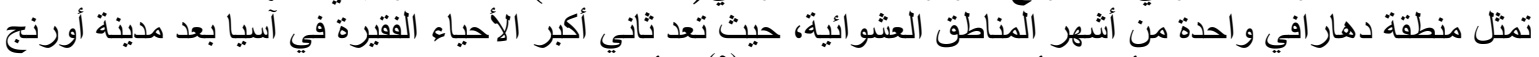
Orangi 
مستنقعات. ونشأت بسبب نقل المصانع و المقيمين من وسط المدينة إلي أطر افها، ومن هجرة الريفيين إلى منطقة مو مباي

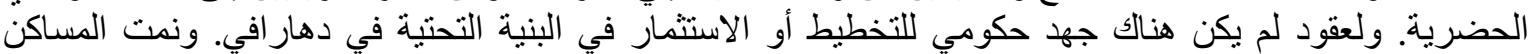

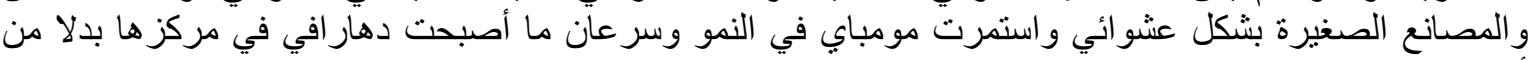

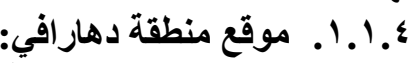

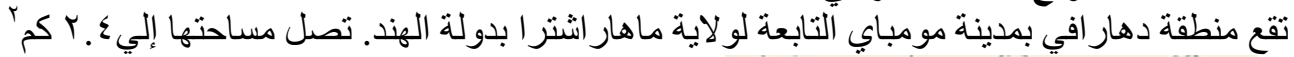

(v)

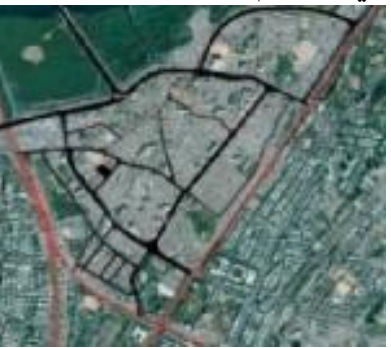

شكل ؛ : صورة جوية لاهارفي

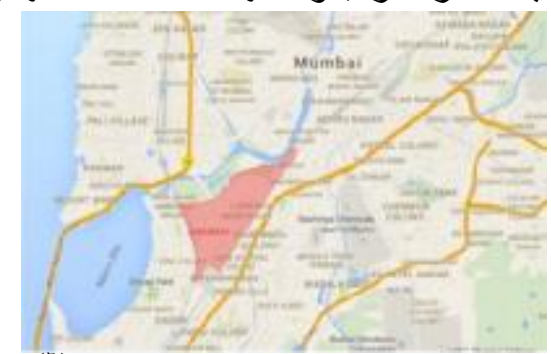

شكل rا: موقع منطقة دهارفي من مومباي (†)

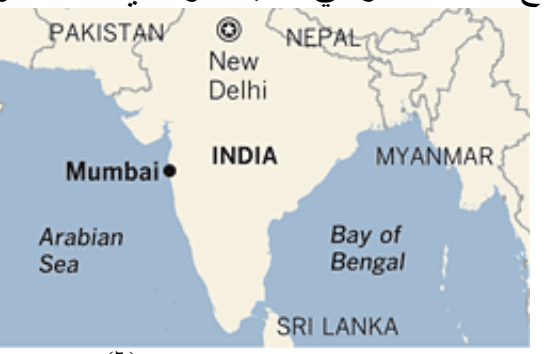

شكل ץ: موقع مدينة مومباي بالهند (")
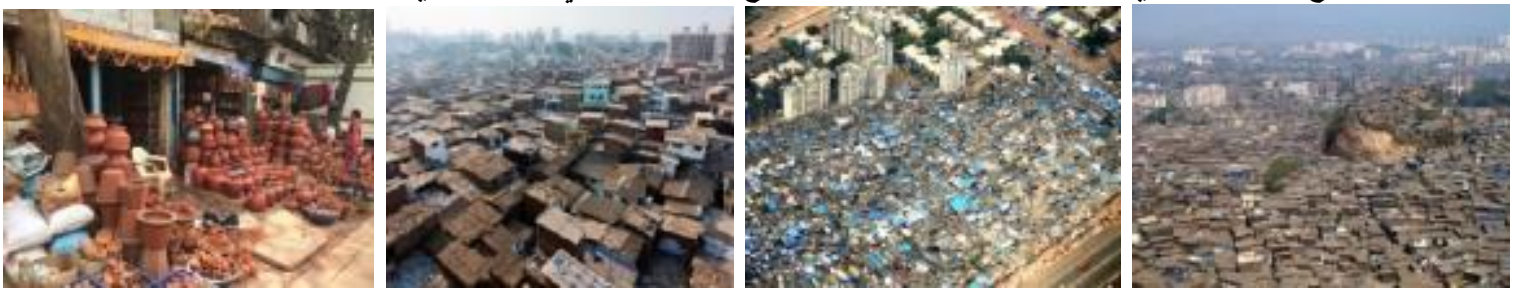

شكل ه: صور توضح الوضع الراهن وتقارب الوحدات السكنية وصغرمساحتها والأنشطة الاقتصادية بمنطقة دهار في (^)

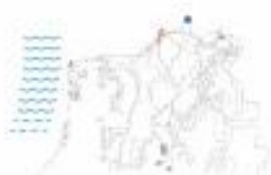

$1 \wedge \ldots$

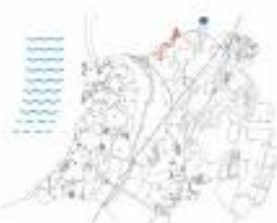

$1 \wedge 7 \varepsilon$

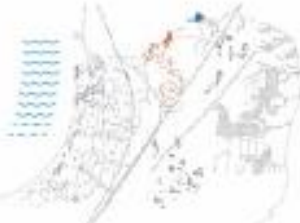

$1 \wedge 9 \vee$

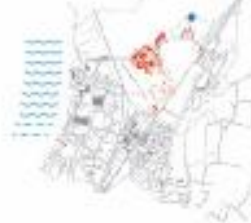

$194 \pi$

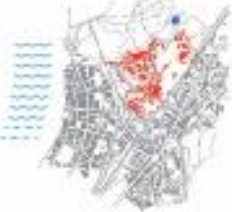

1979

شكل ؟؟: الخط الزمني للتطور العمراني لمنطقة دهارافي (9)

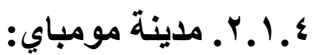

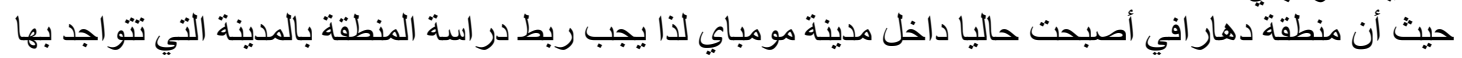

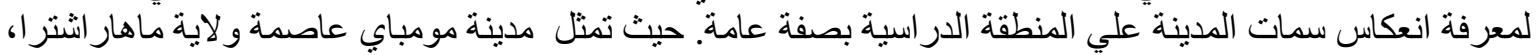

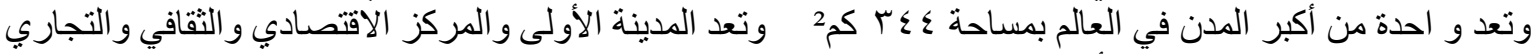

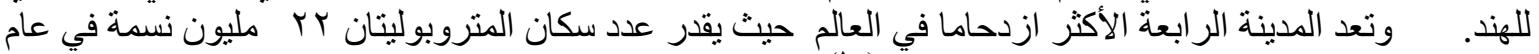

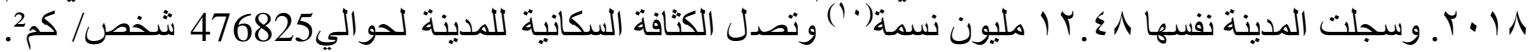

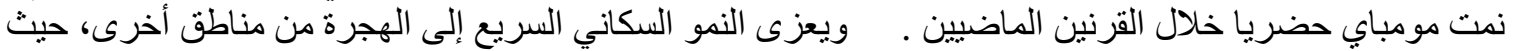

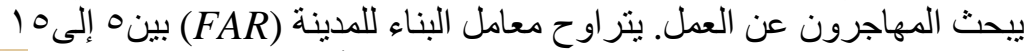

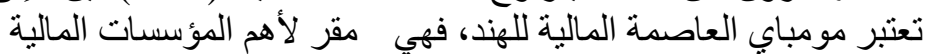

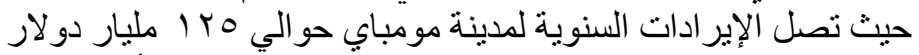

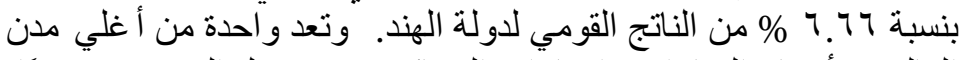

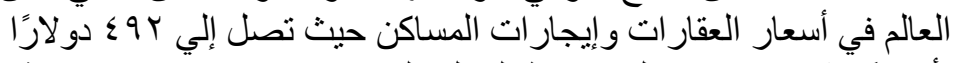

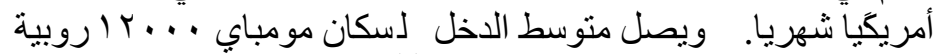

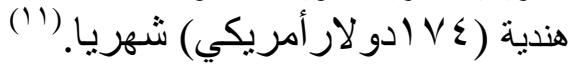

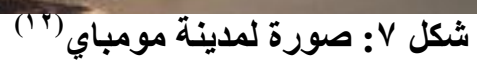

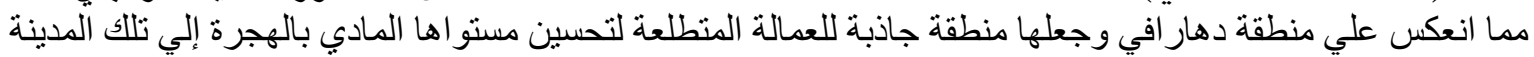
المتميزة اقتصاديا

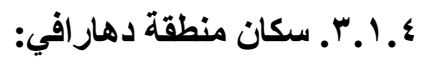

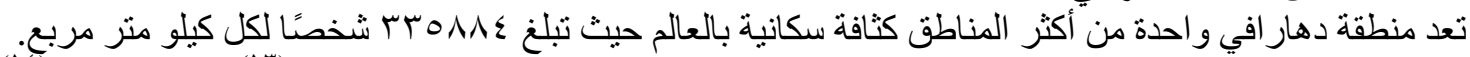

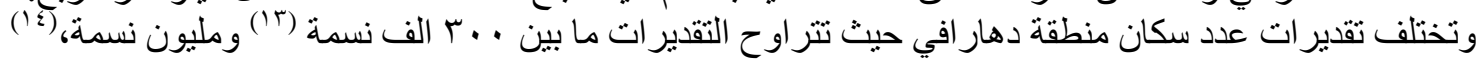

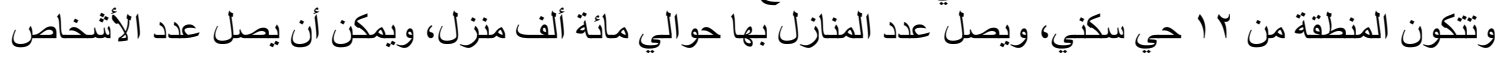




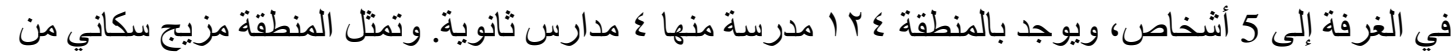

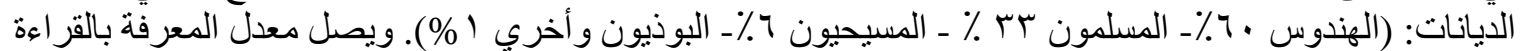
و الكتابة بالمنطقة لحو الي 79 \% ،

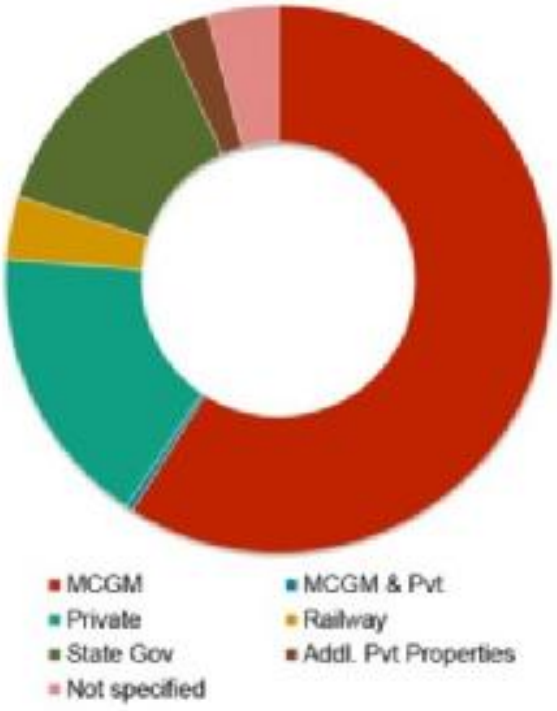

بيان ا : توزيع الملكيات لمنطقة دهارافي(9)

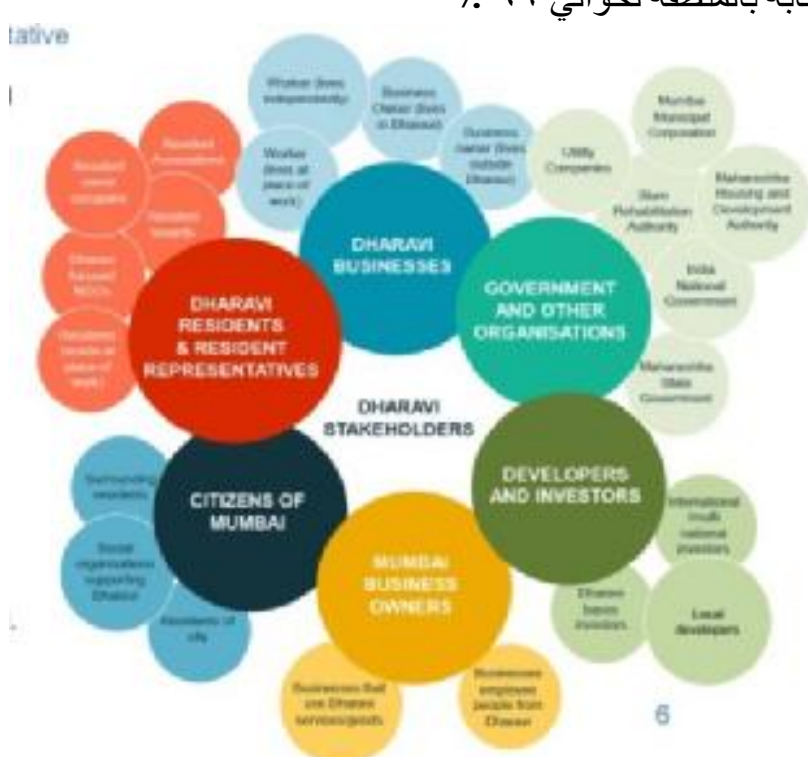

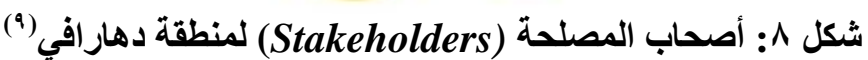
؛ ـ. ـــ النشاط الاقتصادي لمنطقة دهار الافي:

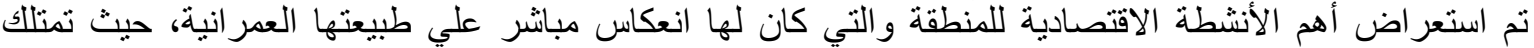

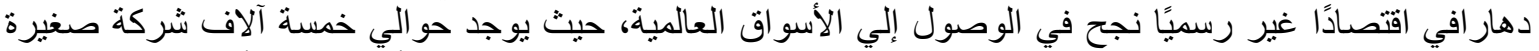
ومتوسطة

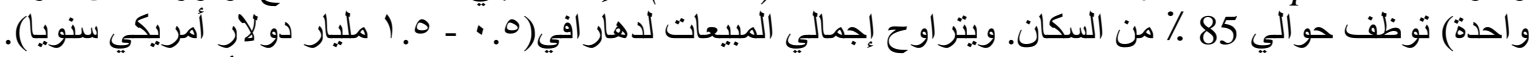

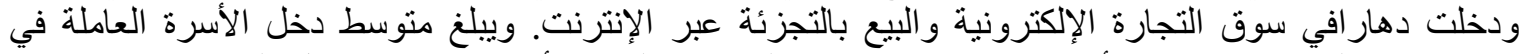

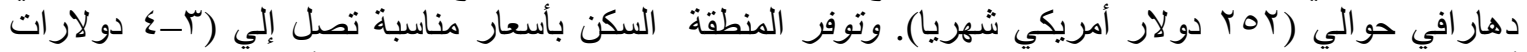

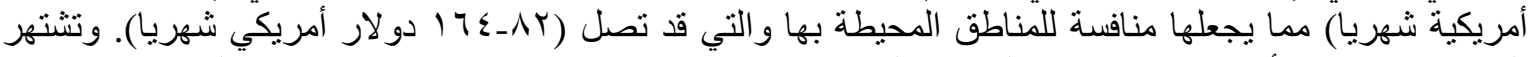

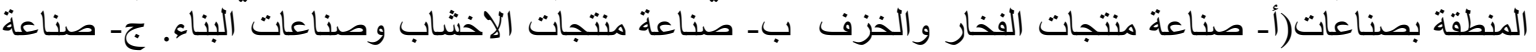

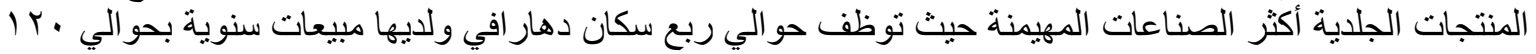

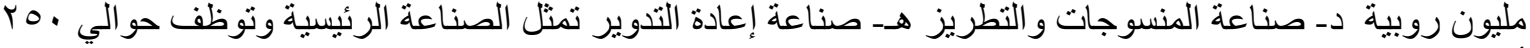
ألف شخصن من رونة

تقع منطقة دهار افي بالقرب من أنشهر و أهم المباني بمدينة مومباي مثل( ICICI Bank و UTI و Citibank، ويصل

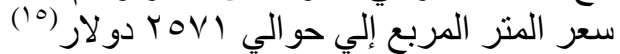

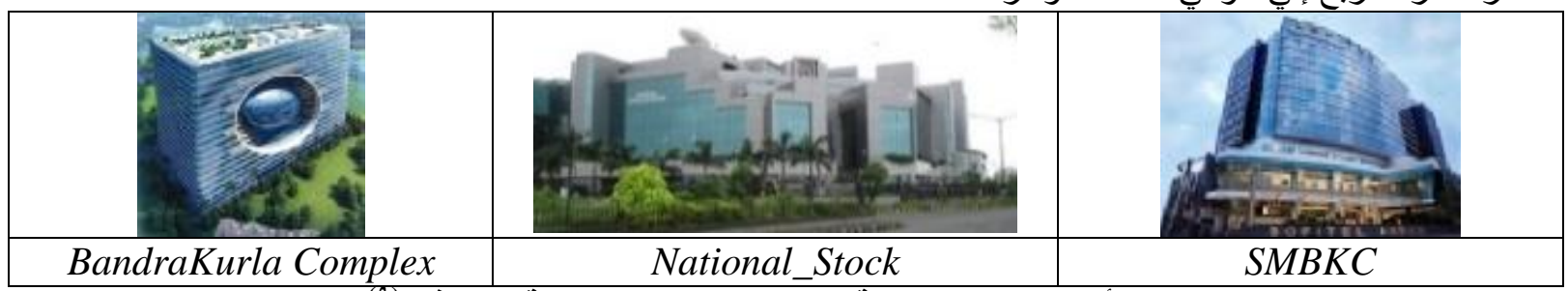

شكل 9: أشهر المباني بمدينة مومباي المجاورة لمنطقة دهارافي (9)

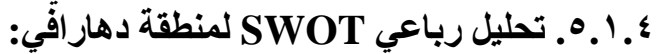
بالجدول النالي تم استعر اض نقاط القوة بالمنطقة لتوظيفها في مشاريع التطوير و الفرص المتاحة لاستثمار ها وكذللك استعر اض نقاط الضعف لمعالجتها و التهديدات المحتملة لتجنبها. 


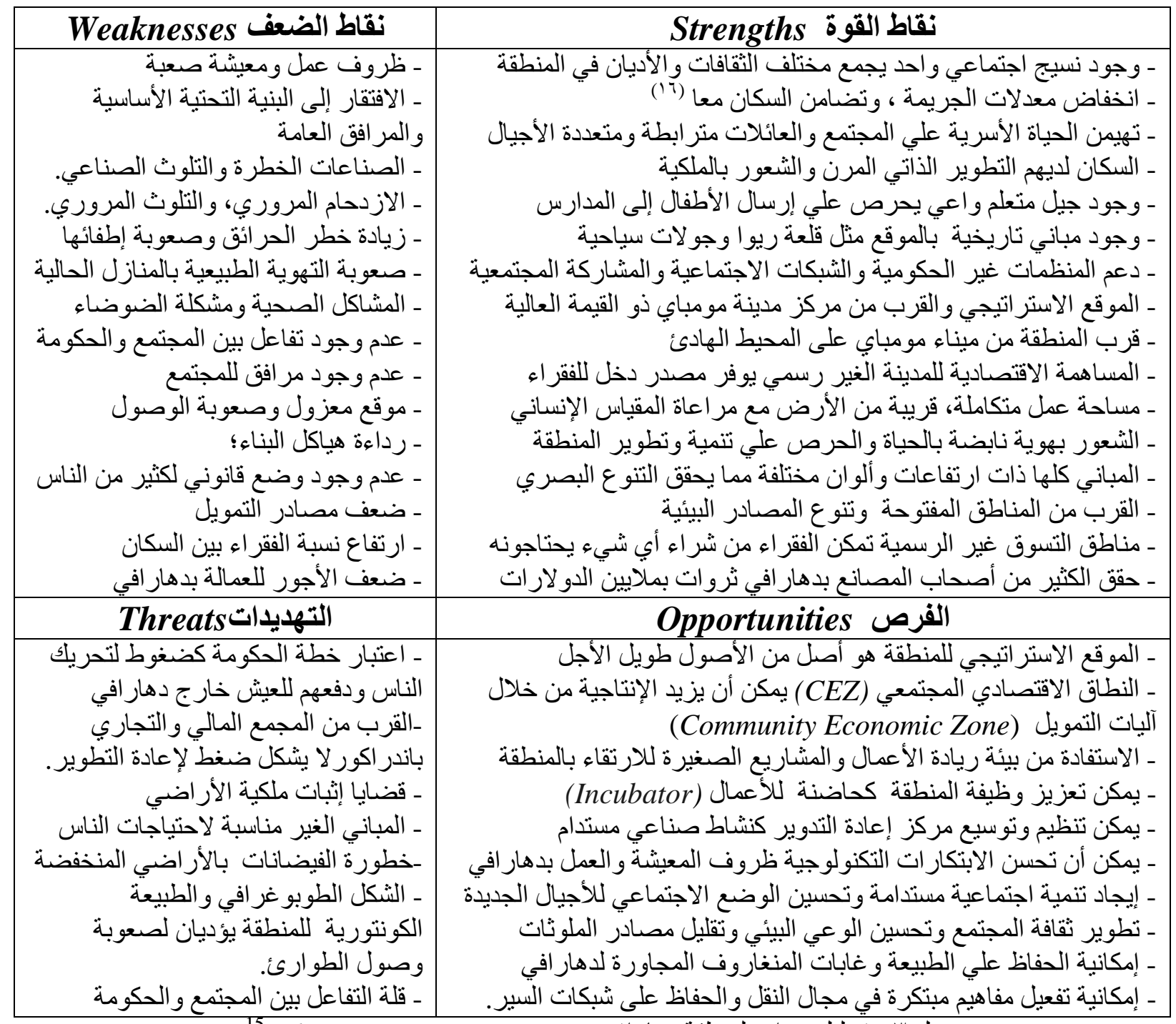

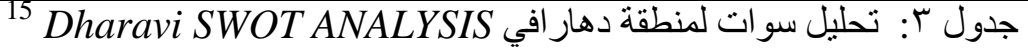

צ. ا.ج. المقترح المعتمد من حكومة ماهار اشترا (مشروع إعادة تطوير دهار افي) (DRP):

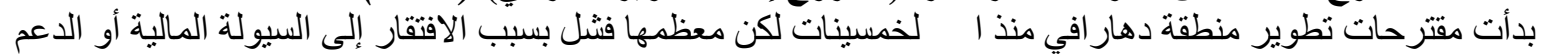

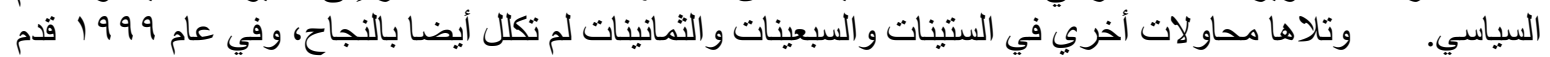

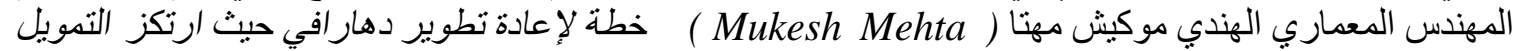

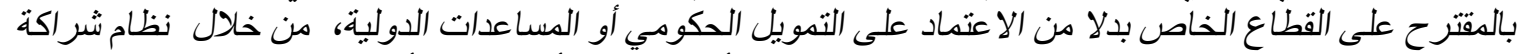

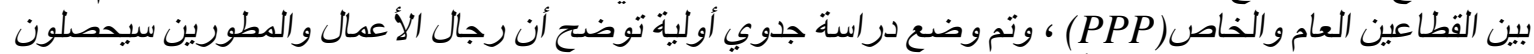

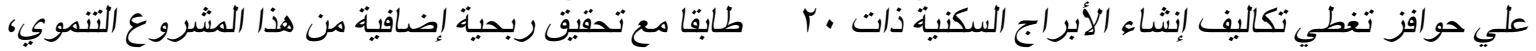

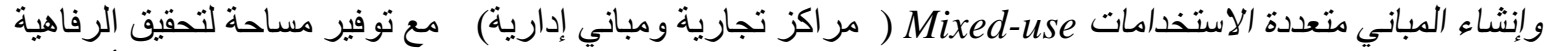

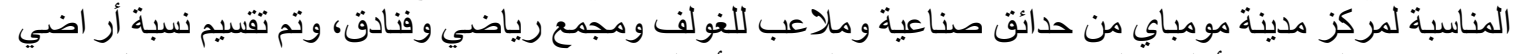

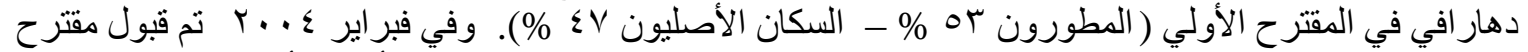

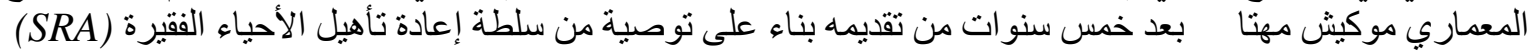

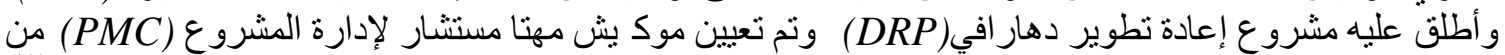
خلال شركته استشاريون للمشاريع الكبرى بمومباي (M)

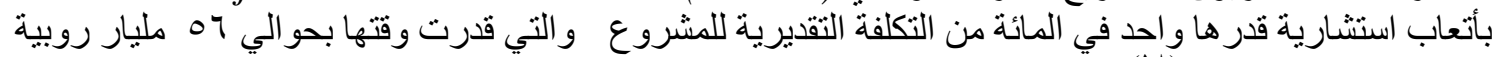

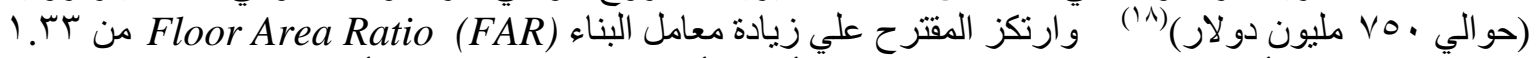

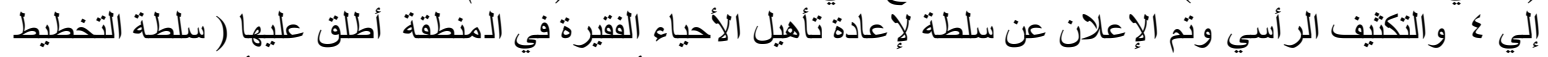

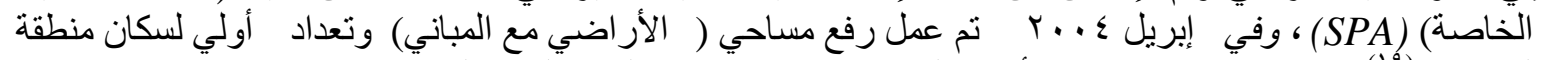

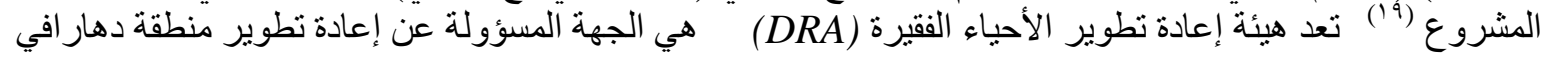

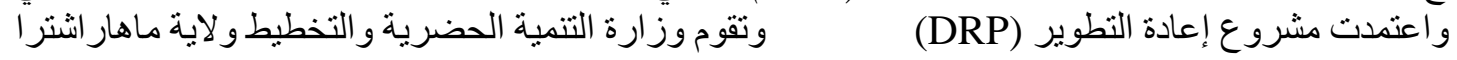




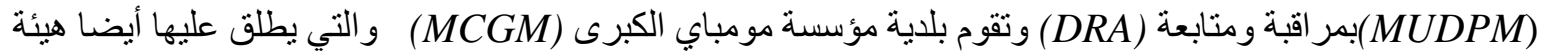
بريهان مومباي البلدية (BMC) بتحديد أهلية سكان الأحياء الفقيرة.

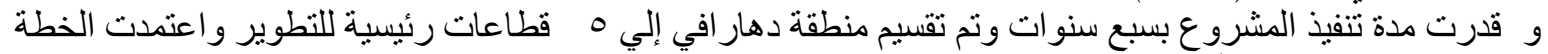

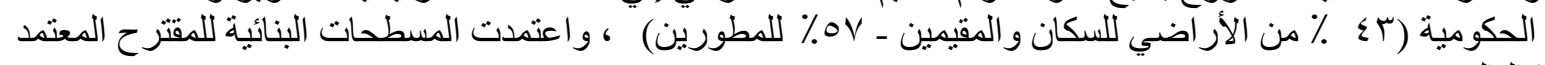

\begin{tabular}{|c|c|c|}
\hline الاستخدام & زيادة المسطحات & المساحات \\
\hline 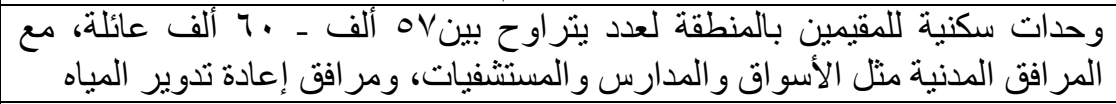 & هr.r مليون م & 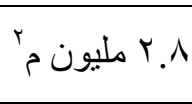 \\
\hline (وحدات سكنية وتجارية وإدارية ). & 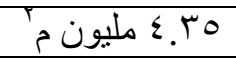 & V. "r مليون م \\
\hline
\end{tabular}

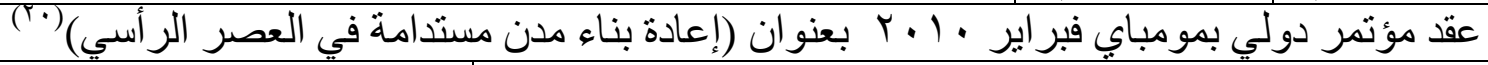

\begin{tabular}{|c|c|}
\hline 10. & $\begin{array}{c}\text { CTBUH } 21010 \text { World Conference-india } \\
\text { nemaking Sustainable Cities in the Vertical Age) }\end{array}$ \\
\hline
\end{tabular}

قدم موكيش مهنا Mukesh Mehta ورقة بحثية بالمؤتمر عرض فيها مشروع التطوير المعتمد DRP

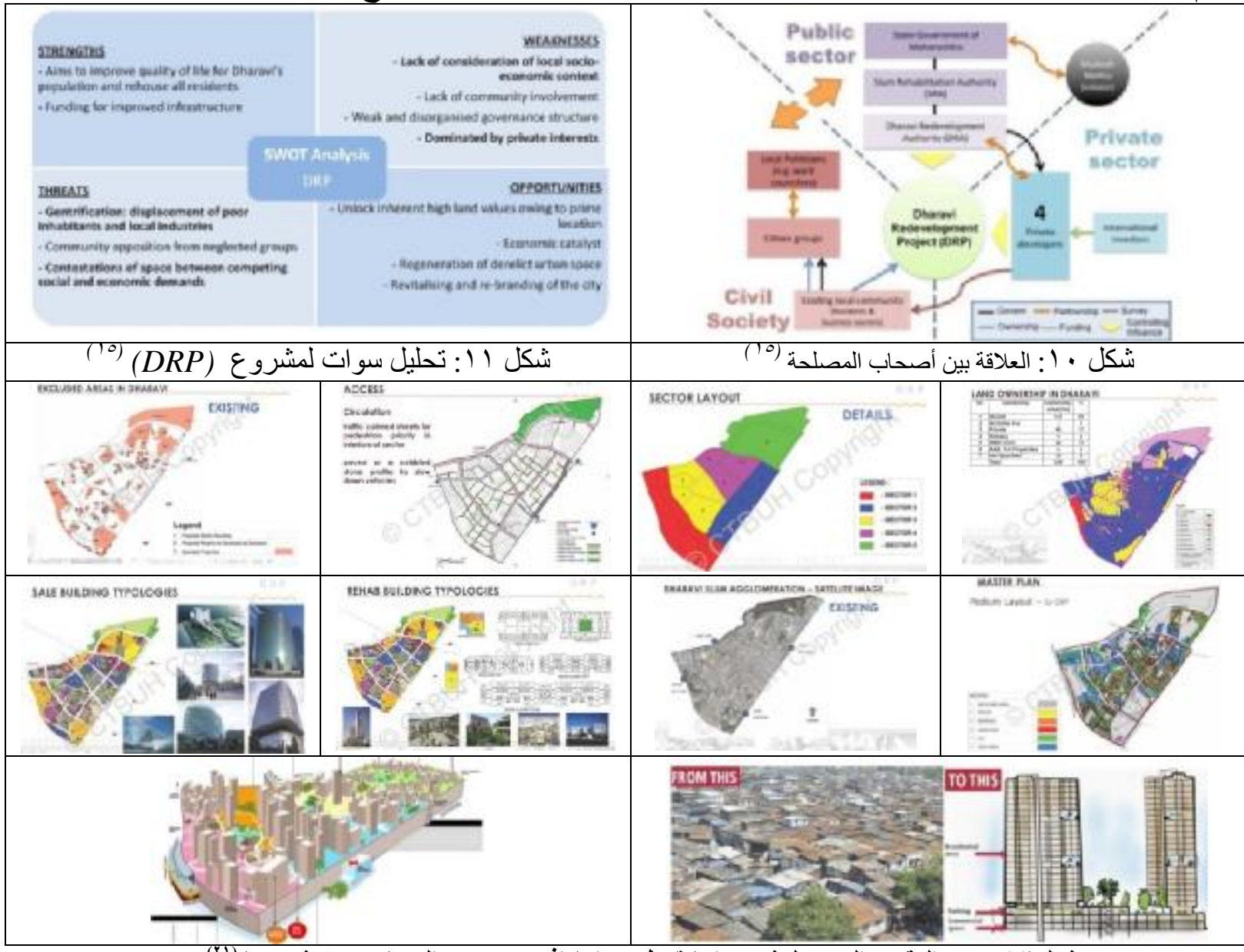

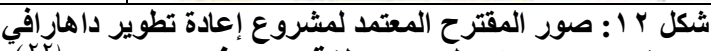

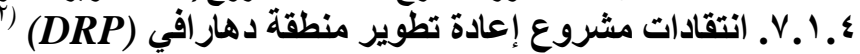

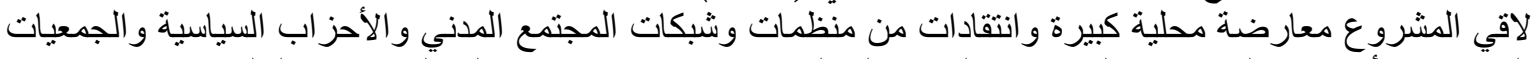
المجتمعية و أصحاب الصناعات الصغيرة و السكان المحليين وكانت اعتر اضاتهم علي المشروع كالتالي: 
أولا: غياب المشاركة المجتمعية فيDRP حيث أعدت خطة المشروع بطريقة تكنوقراطية بأسلوب التخطيط الفوقي (من أعلي لأسفل DRP حيث تم فرضه علي الناس وعلدم اتباع منهجية التخطيط التشاركي (PD)

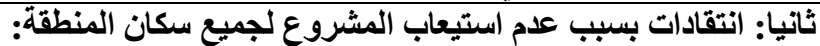

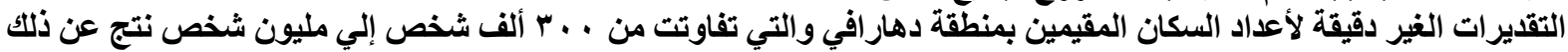

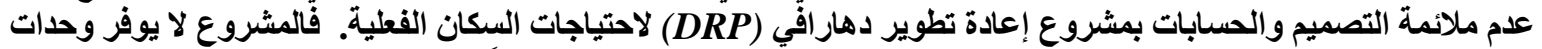

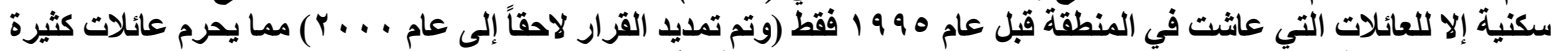

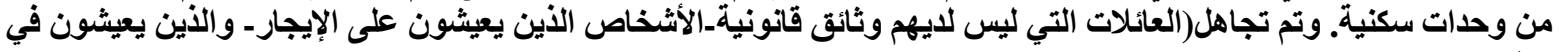
(الطوابق العليا)

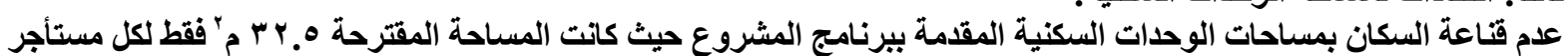

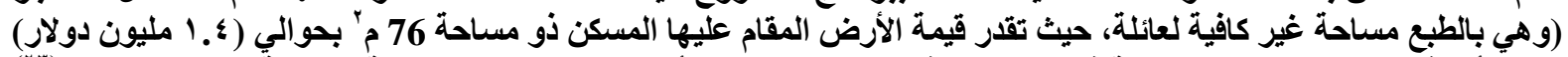

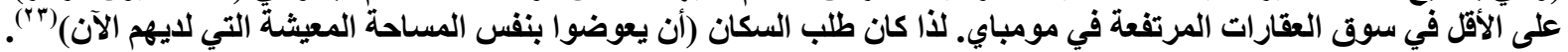

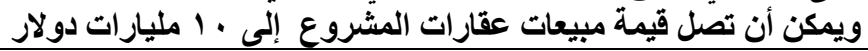

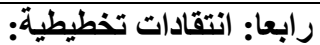

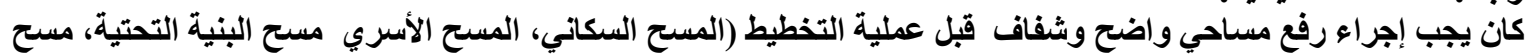

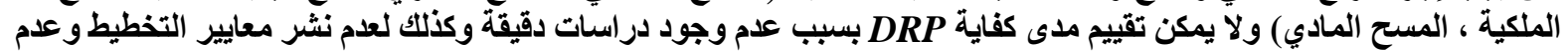

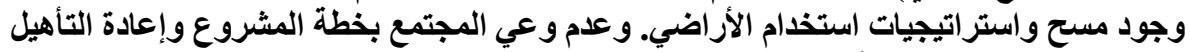

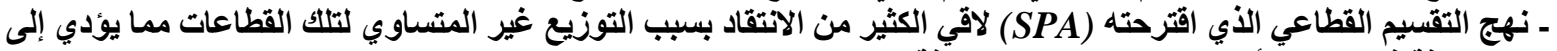

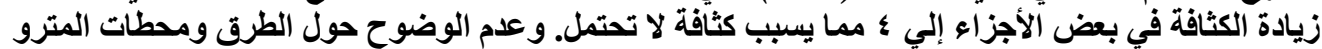

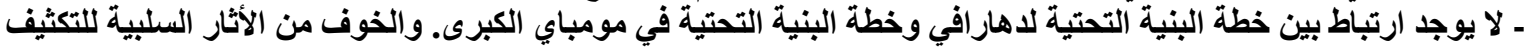

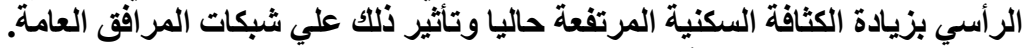

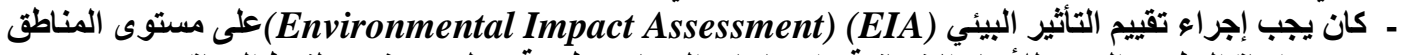

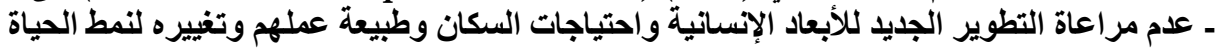

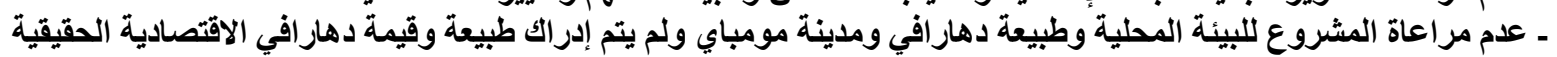

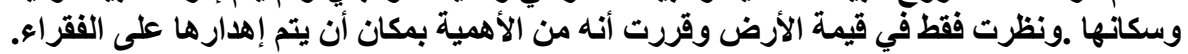

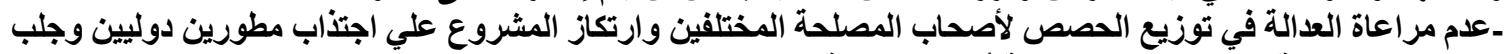

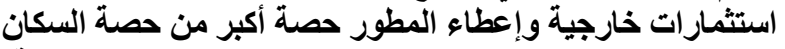

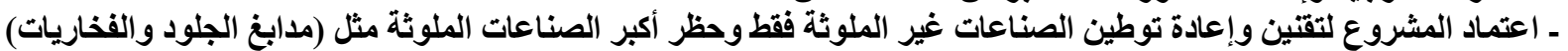

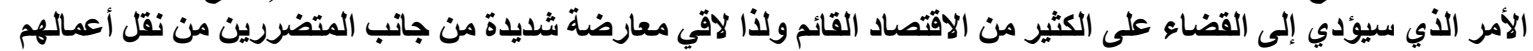

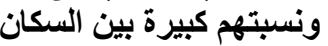

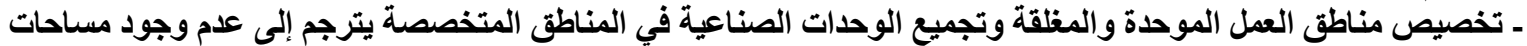

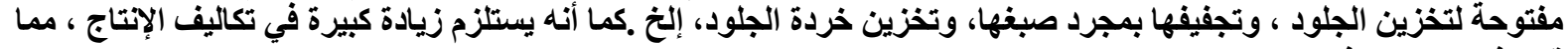

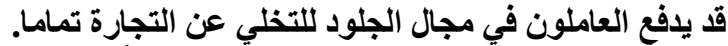

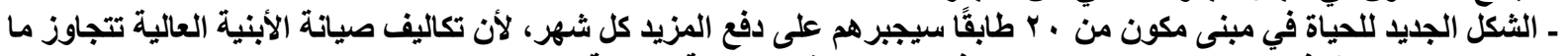

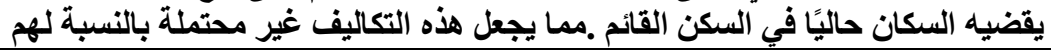

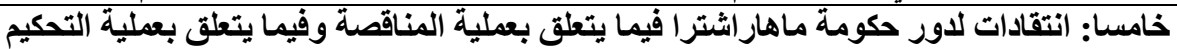

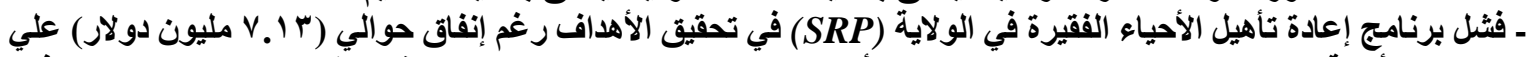

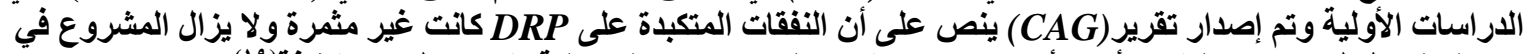

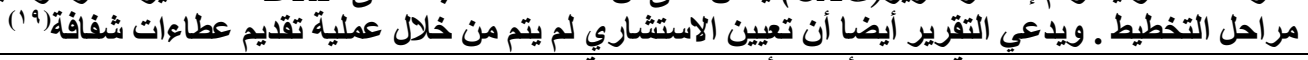

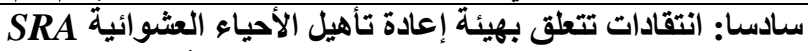

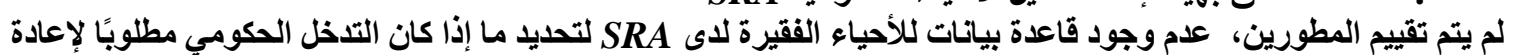

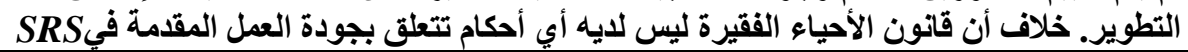

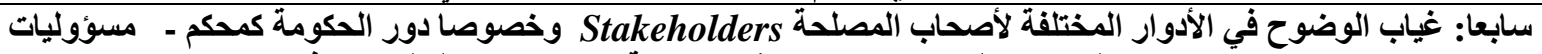

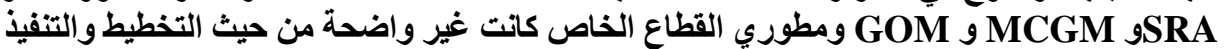

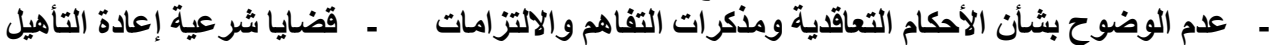

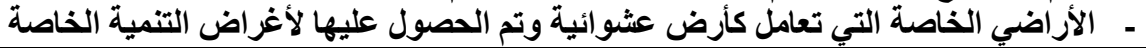

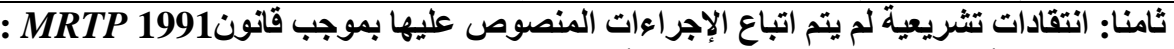

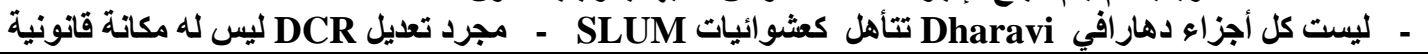
جاول ؛ : انتقادات مشروع إعادة تطوير منطقة دهار افي (DRP)

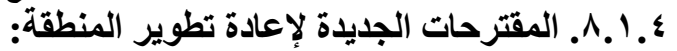

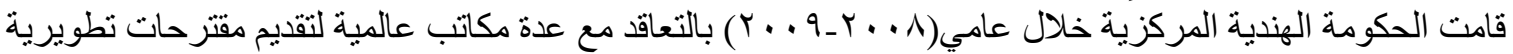

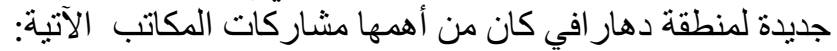
أـ مقتر ح مكتب فوستر وشركاه (Foster + Partners) 
نحو تنمية مستدامة متعددة الاستخدامات ذات بعد إنساني للمناطق العشو ائية بمر اكز المدن در اسة مقارنة لمشاريع إعادة تطوير منطقتي (دهار افي، مومباي

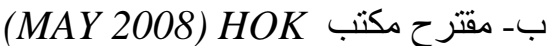

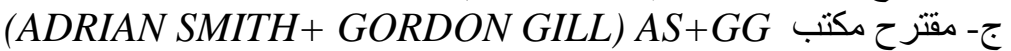
د- مقتر ح مكتب م حفيظ (ARCHITECT HAFEZ CONRACTOR) أ- مقترح مكتب فوستر وشتركاه

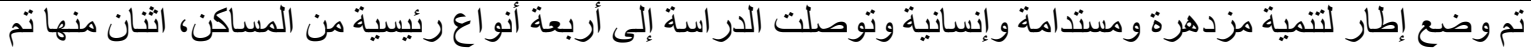

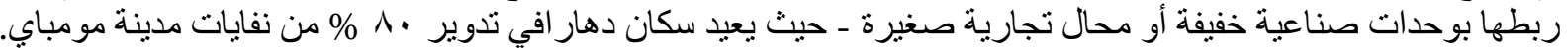

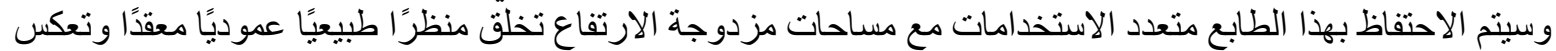

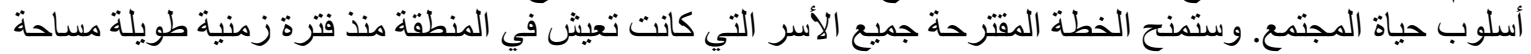

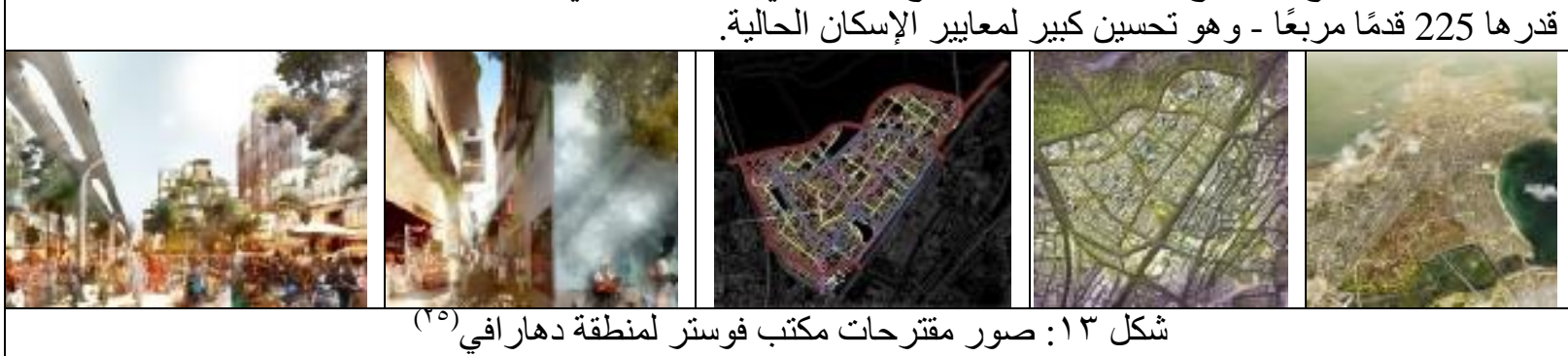

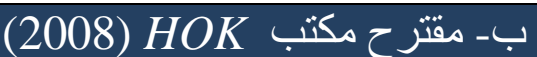
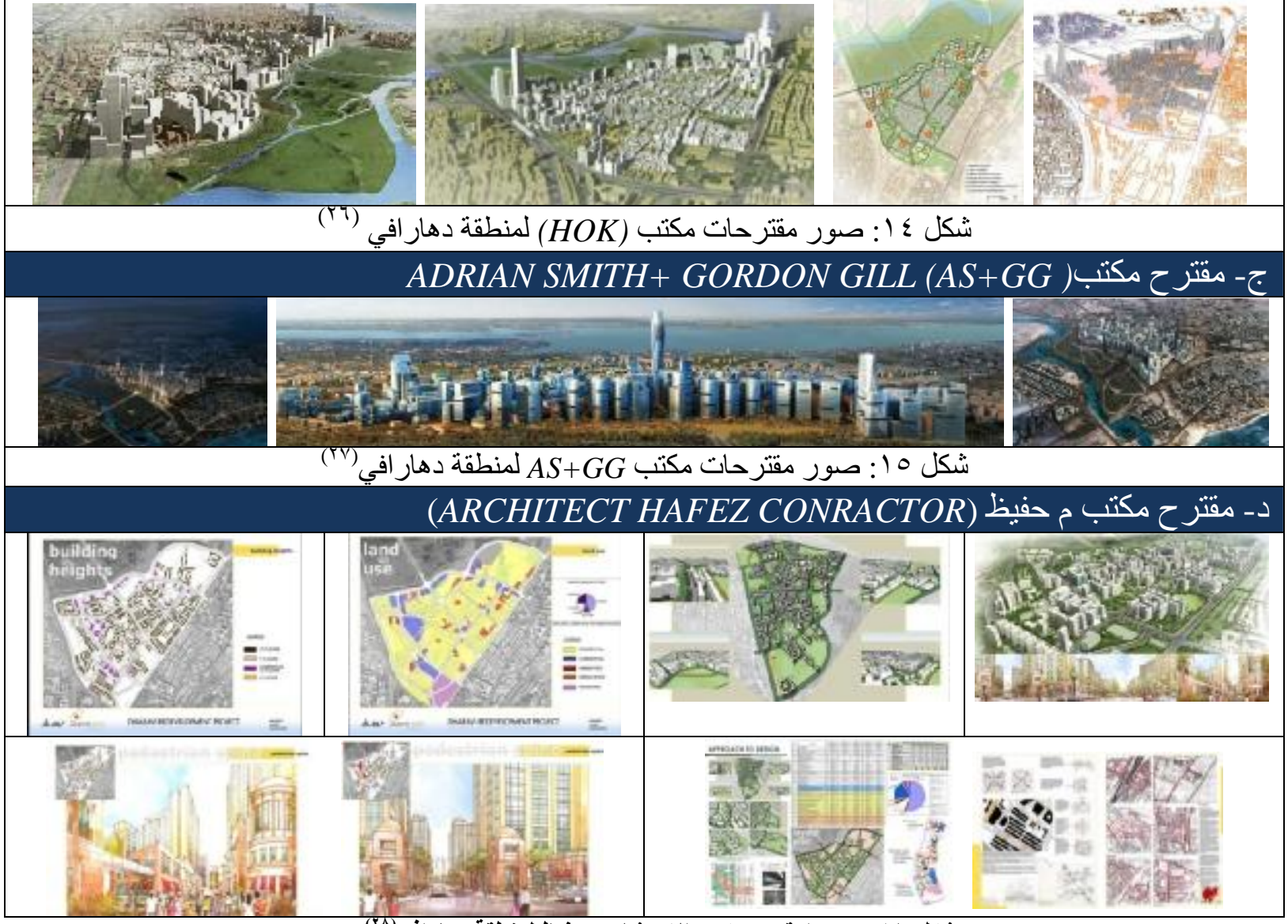

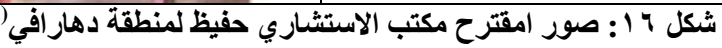

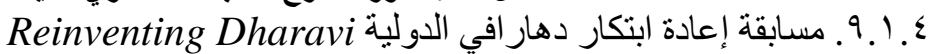

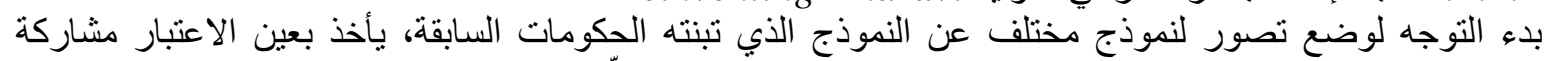

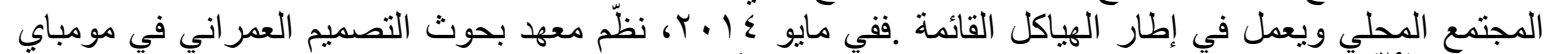
(UDRI)

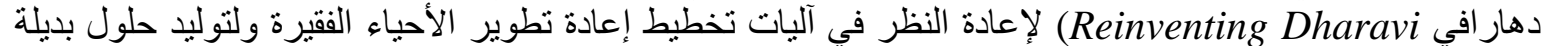

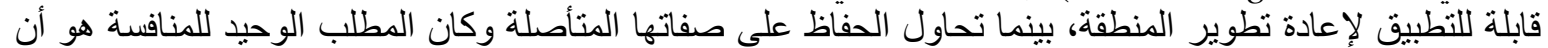

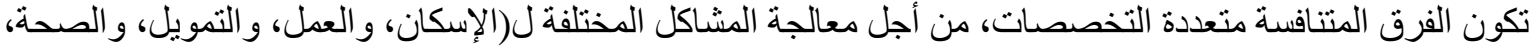




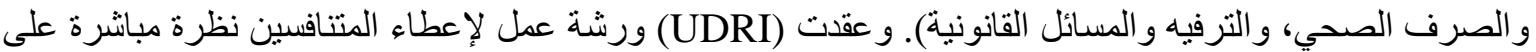

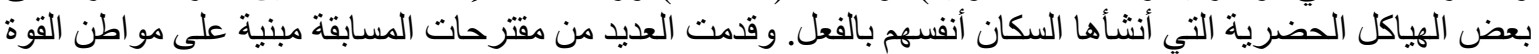

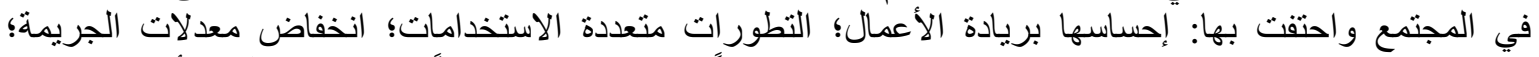

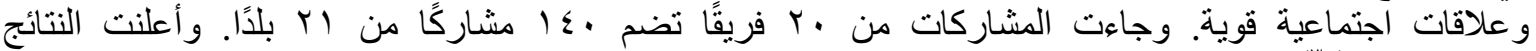

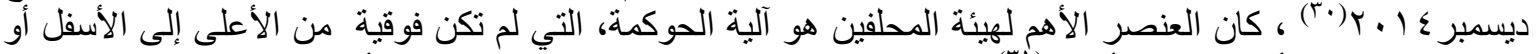

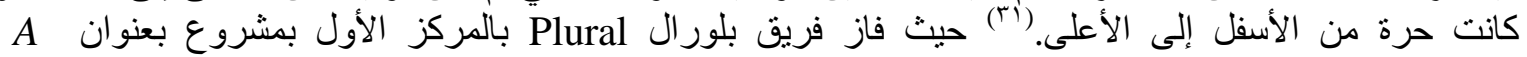
Participative Development Model Dharavi

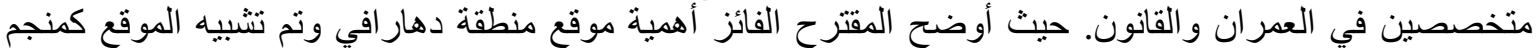

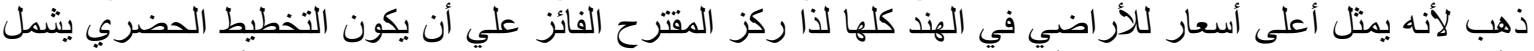

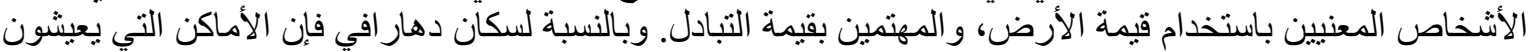

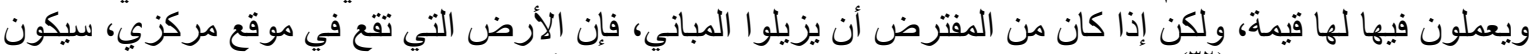

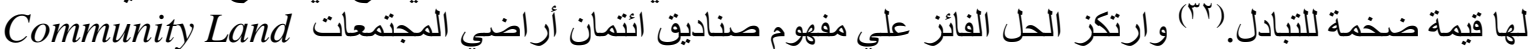
(CLTS) ${ }^{(r T)}$ Trust

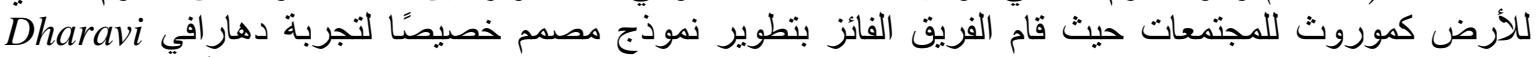
(DCLT)

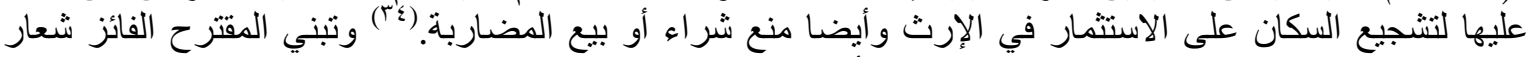

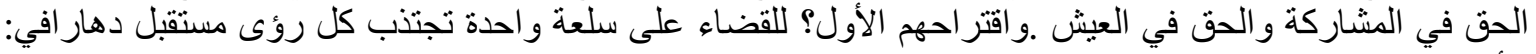
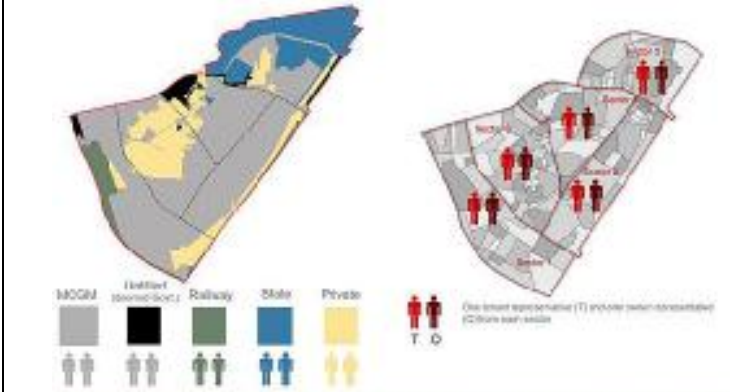

الأرض نفسها.

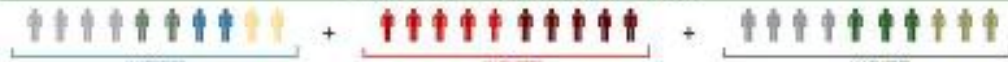

صندوق ائتمان أراضي المجتمع المقترح (DCLT) مؤسسة غير ربحية يحكمها ملاك الأراضي السابقون و أعضاء

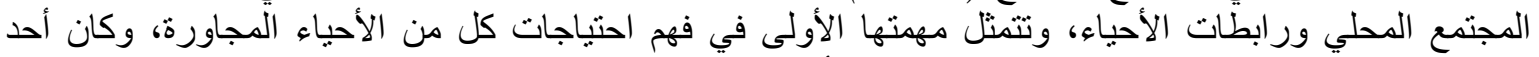

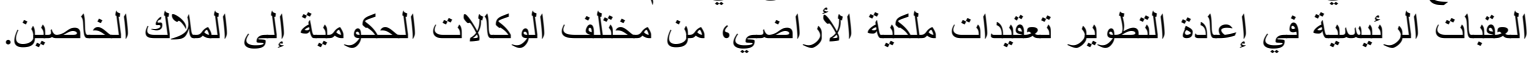

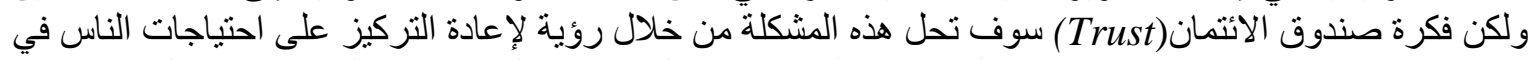

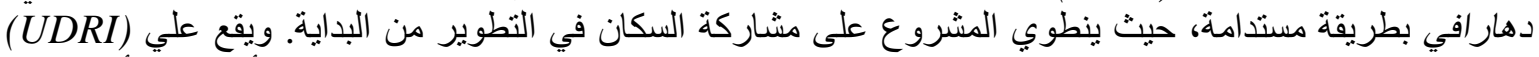

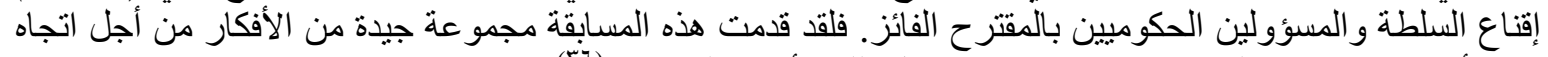

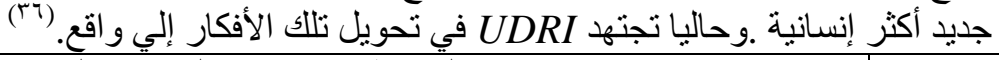

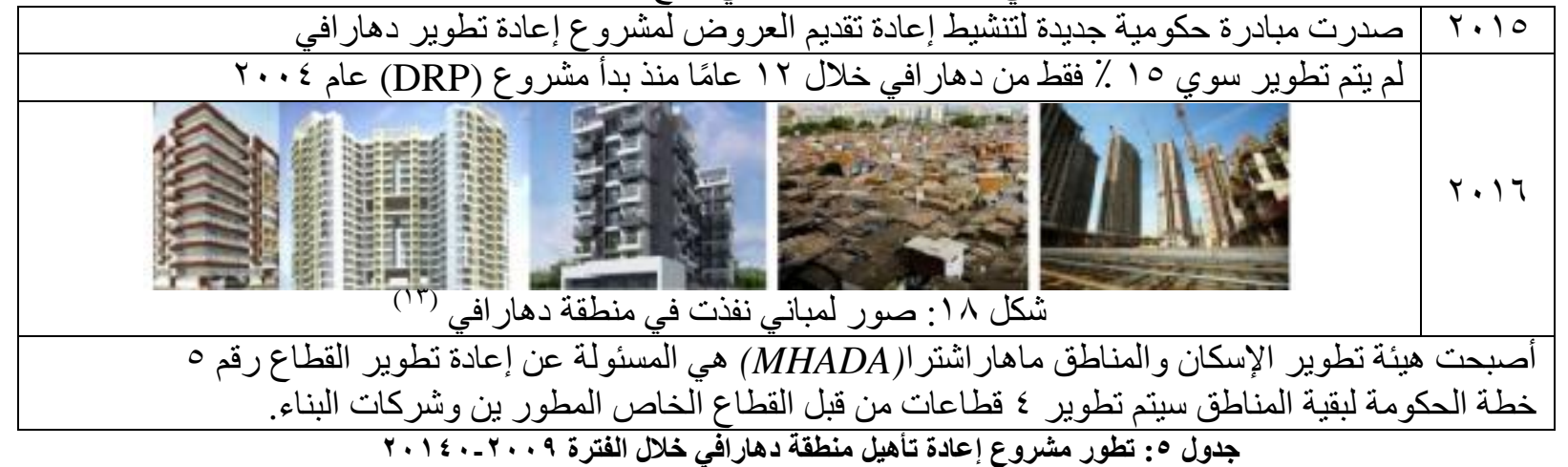


؛. ؟. المنطقة الاراسية الثانية: مشروع تطوير منطقة ماسبيرو بمدينة القاهرة ـ مصر

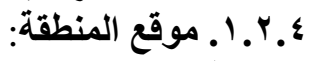

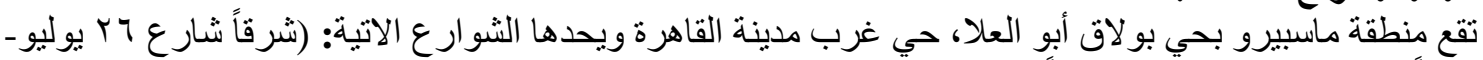

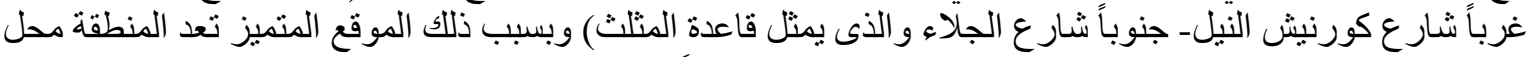

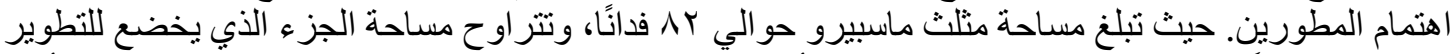

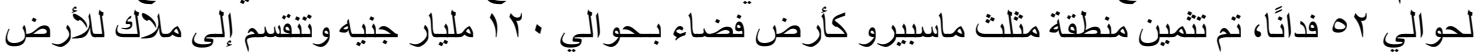
كثركات ومستأجرين وملاك للعقار اته. وقدر عدد السكان بالمنطقة حو الي 18 ألف إنسان لأربعة أجيال مختلفة.

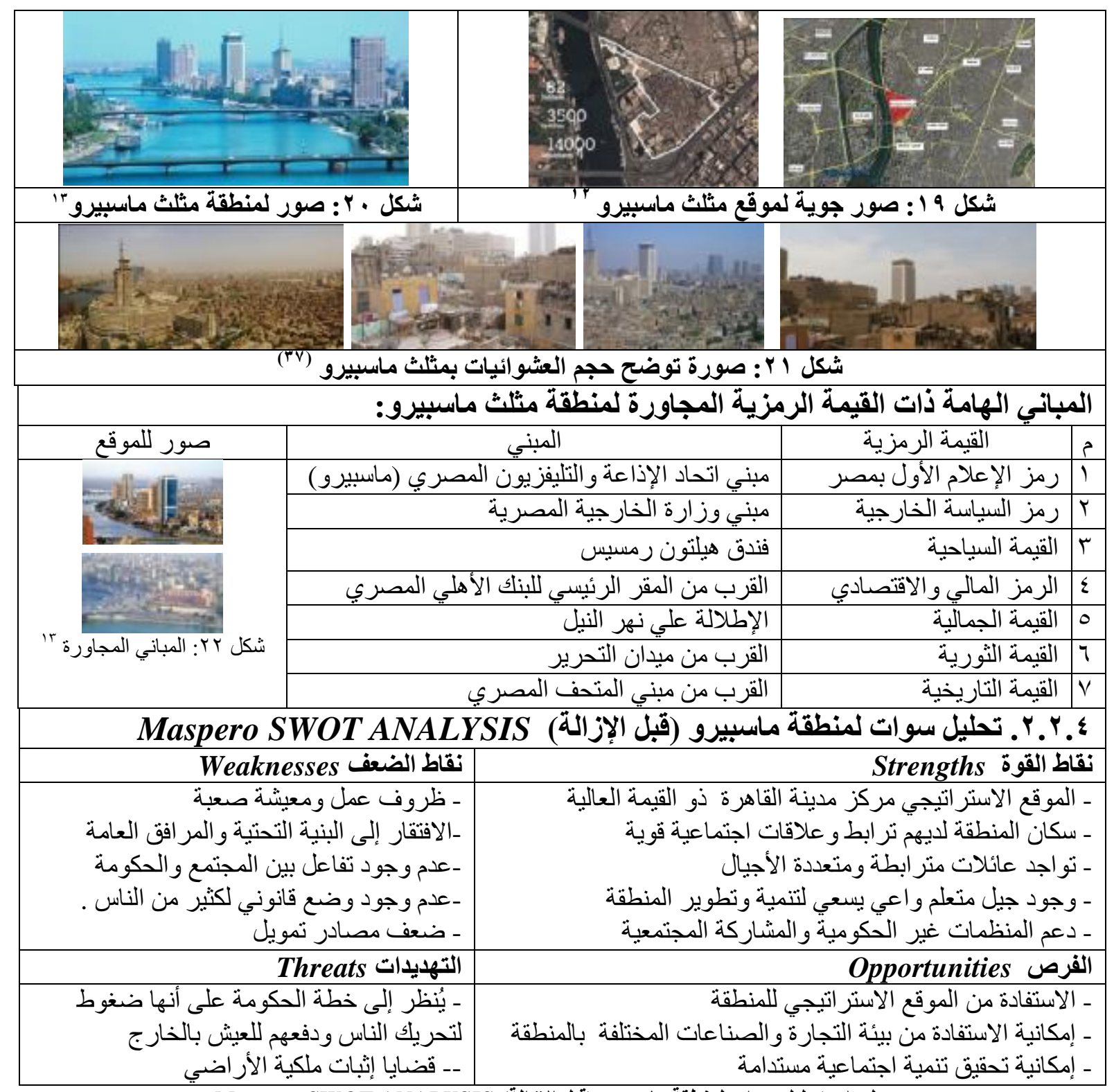

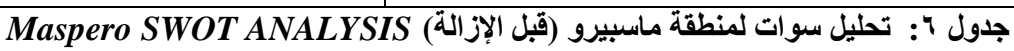




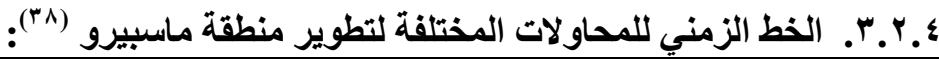

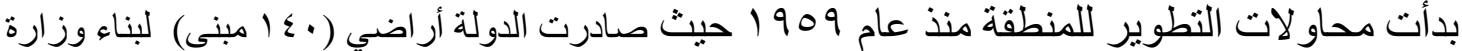

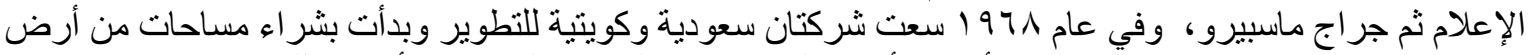

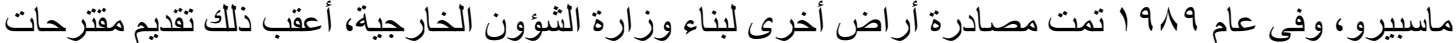

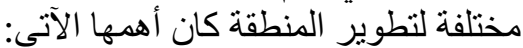

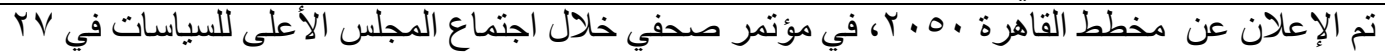

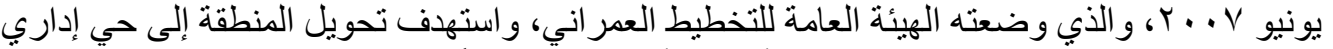
ومالي مميز، تضم المركز المالي للثرق الأوسط و أوروبا، وكمركزًا ثقافيًا وتاريخيًا

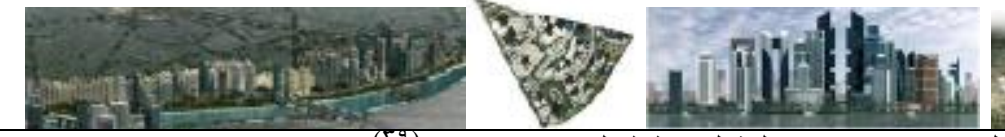

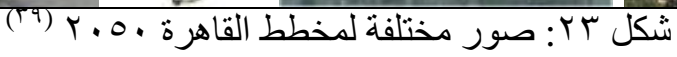

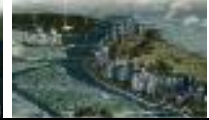

كُّلف المهندس الاستشاري حسام يوسف، بوضع مخطط للمنطقة تضمّن تحويلها بالكامل إلى مباني إدارية

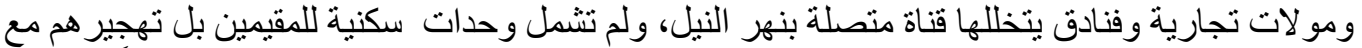
تعويضهم إما بوحدات سكنية على أطر اف القاهرة أو في المدن الجديدة، أو بتعويضات مالية ولية لاحفًا،
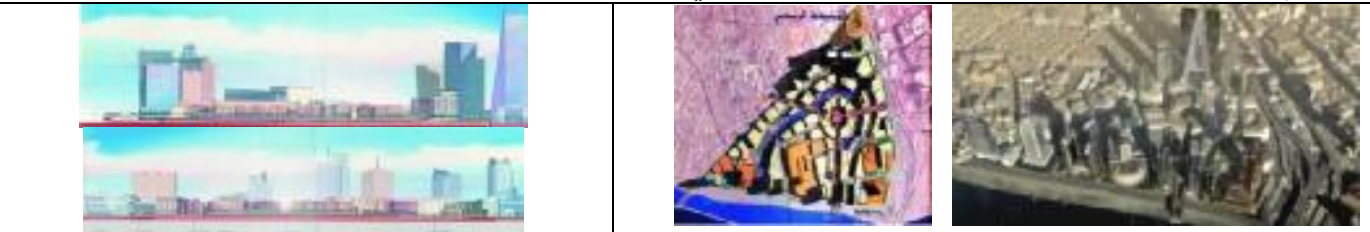

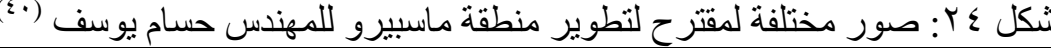

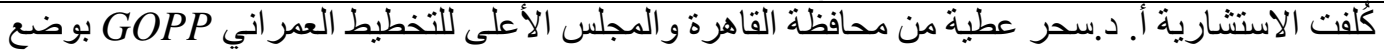
مخطط لمنطقة وسط البلد ثم مثلث ماسبيرو، وتشابه المخطط مع ما جاء في المشرو عين السابقين
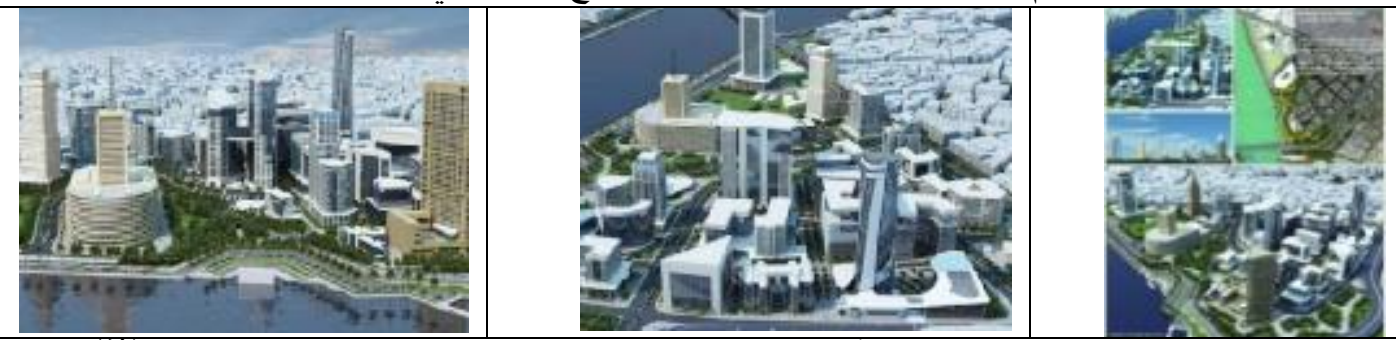

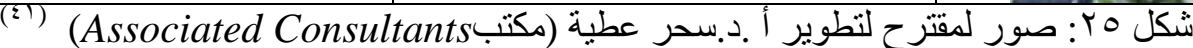

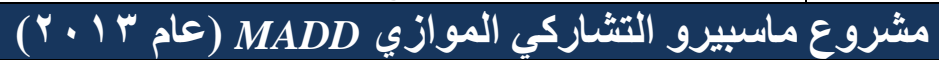

Maspere Parallet Pintiaipatory Projer

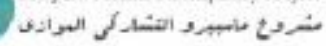

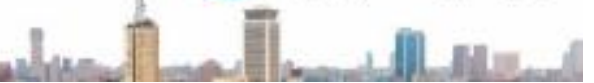

is madd

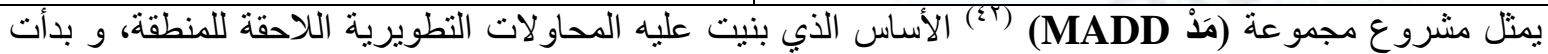
مجموعة العمل في شهر يونيو 2013 بمشروع ماسبيرو التشاركي الموازي(علي مرحلتين، مرحلة البحث التشاركي،

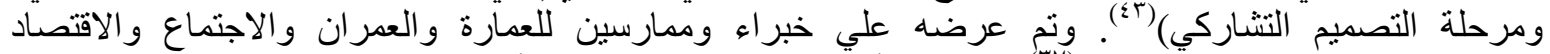
و البيئة،وونم إصدار تقرير الدراسة.

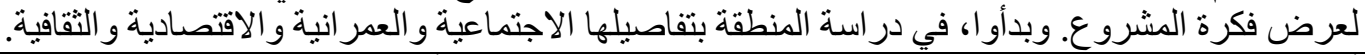

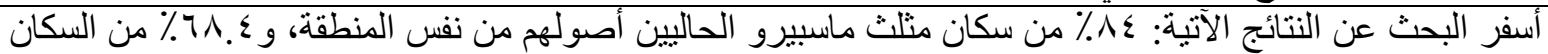

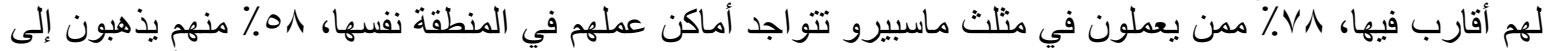

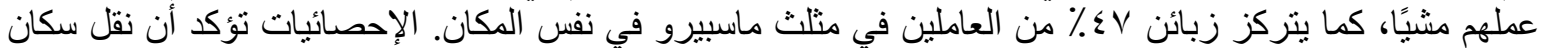

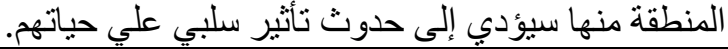

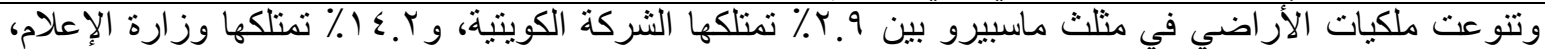

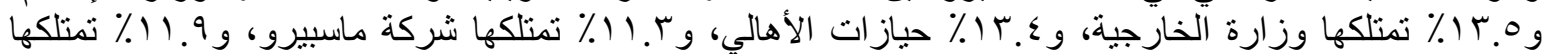

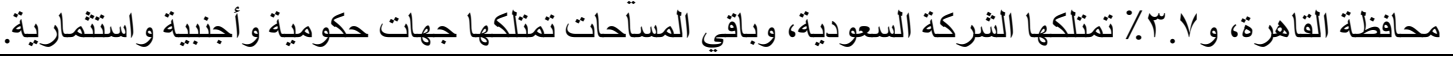




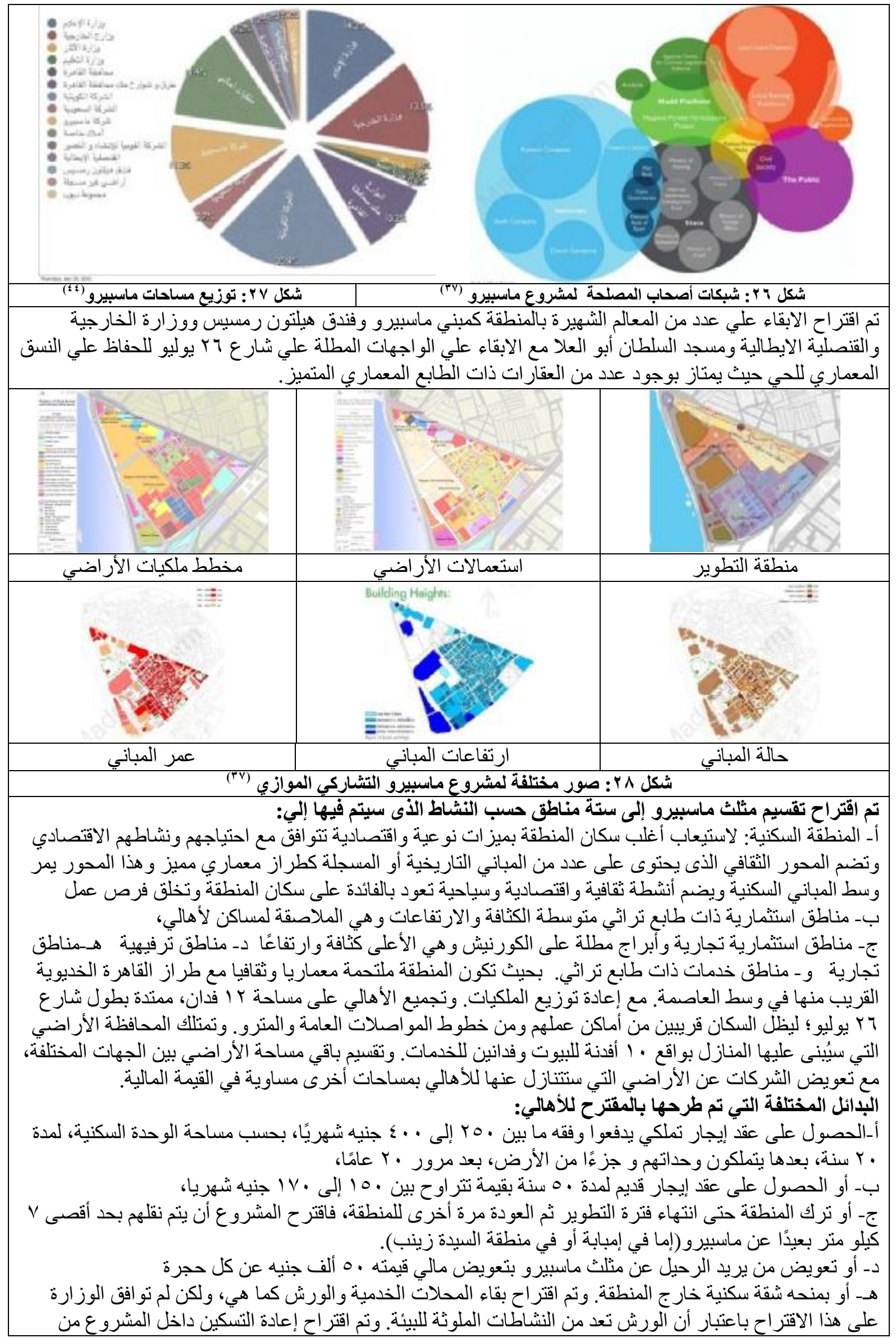




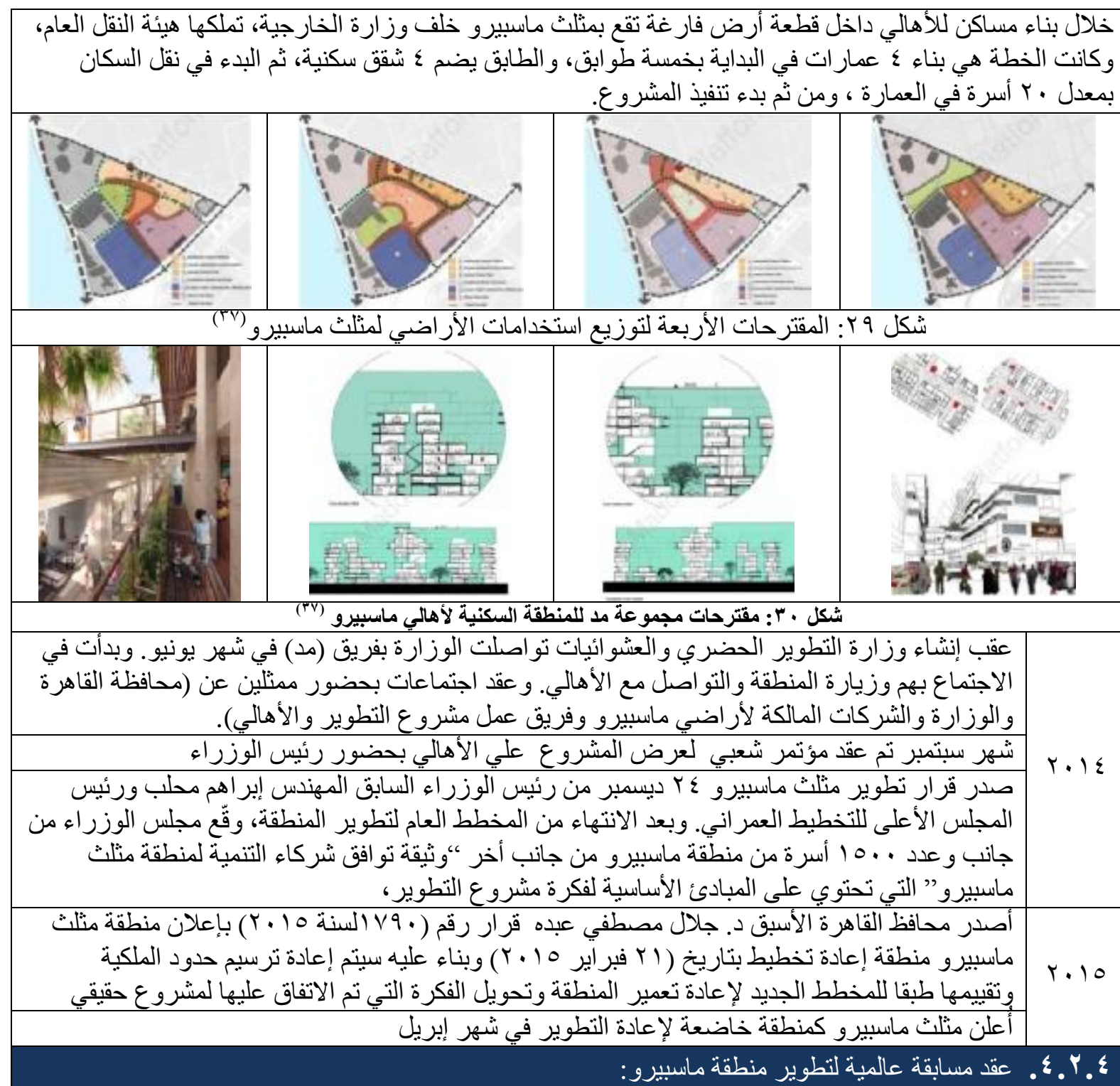

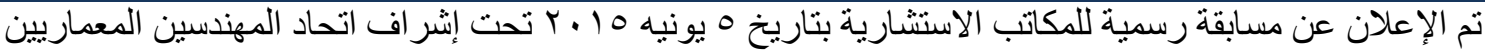

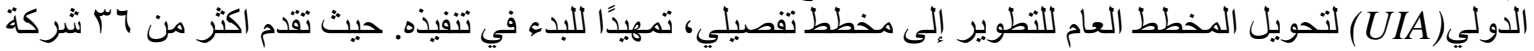

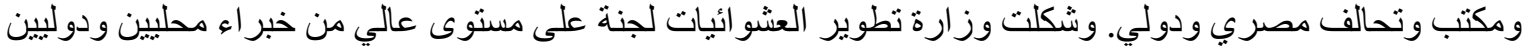

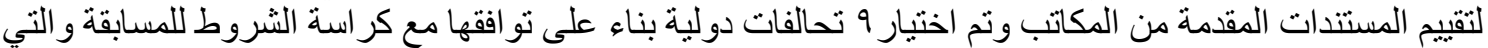

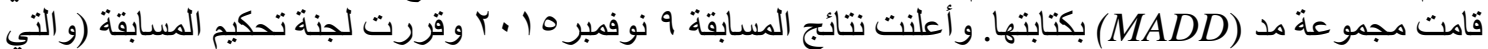

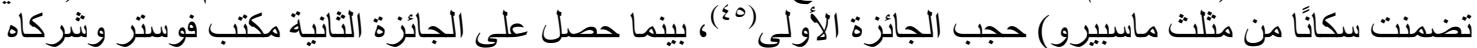

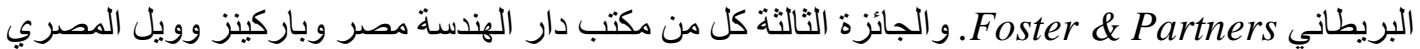
الأمريكي)Dar Al Handasah\& Perkins Will (Egypt, USA) ومكتب ستنفان وبيورى وشركاه الإيطالي . وقدرت التكلفة الأولية للمشروع بحو الي عشرة مليار ات جنيه

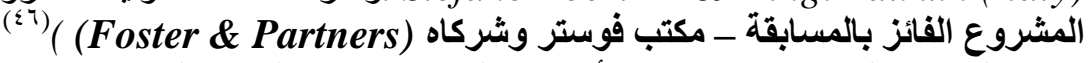

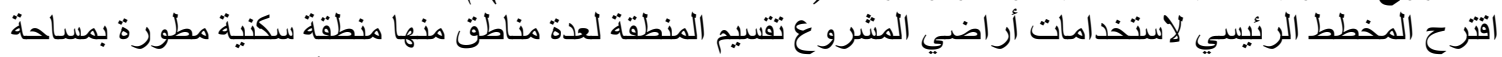

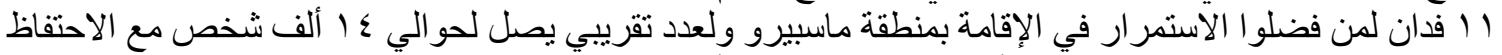

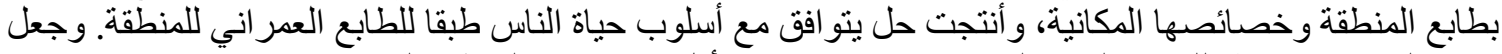

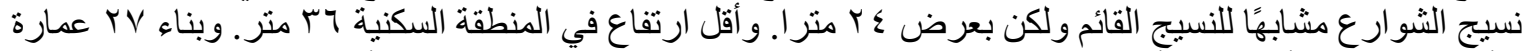

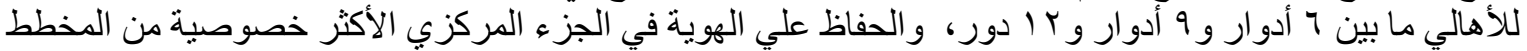

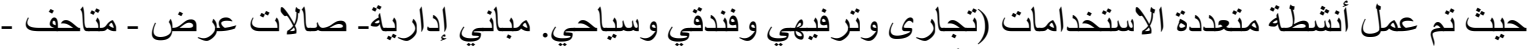

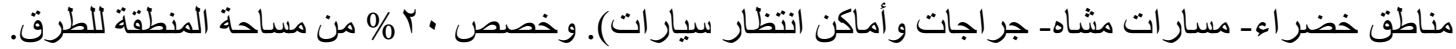
وتضمن المشروع أماكن مخصصة لإقامة الحفلات وجسر مشاه لربط المثلث بحي الزمالك والك وأماكن للنسوق و أماكن 


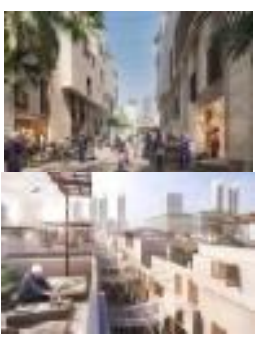

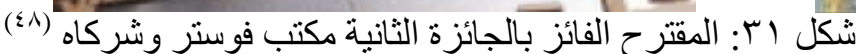

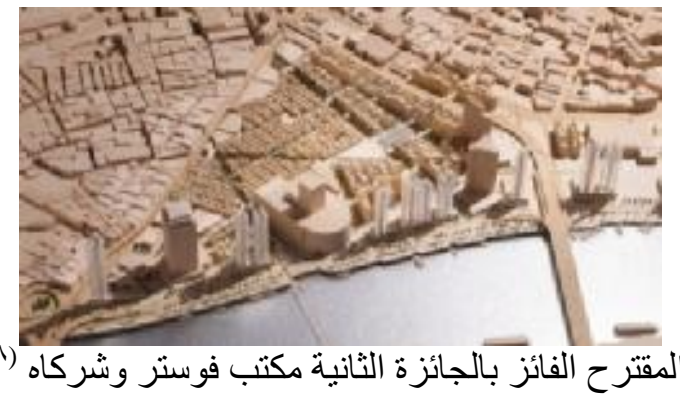

$(\Sigma v)$

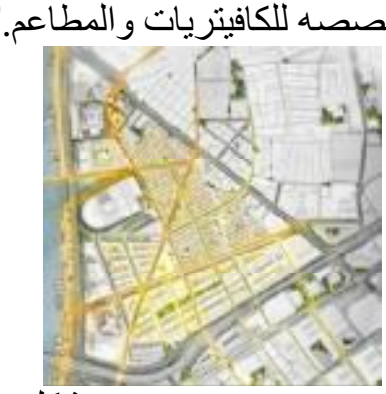

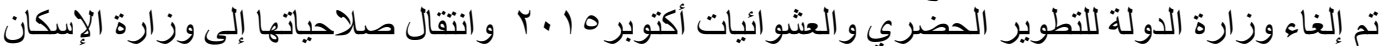

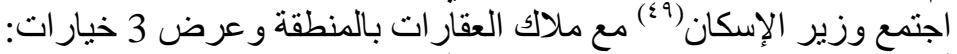

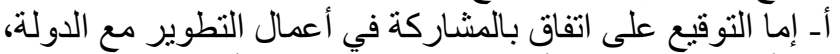

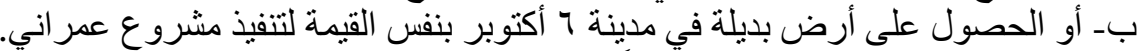

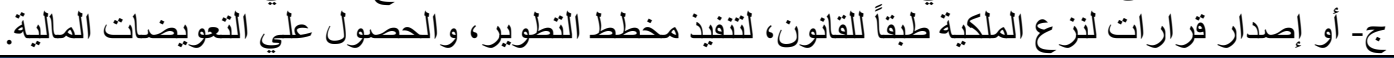

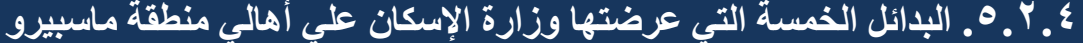

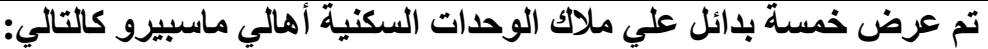

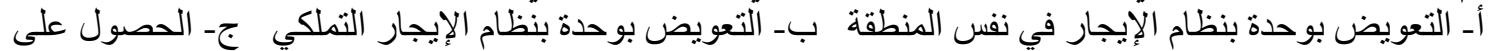

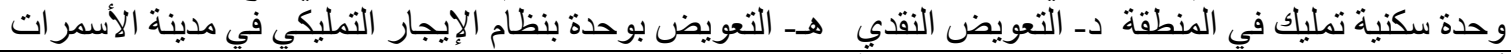

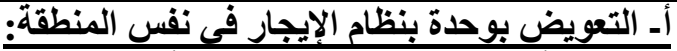

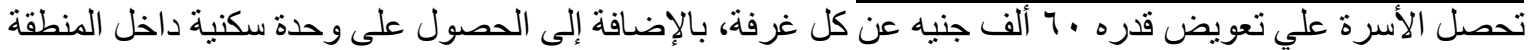

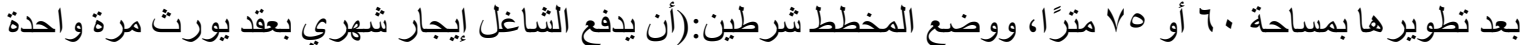

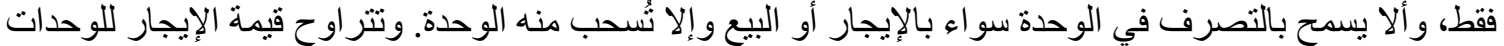

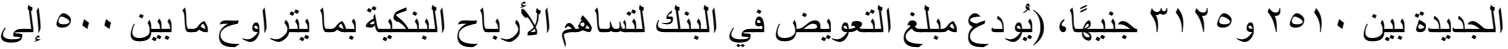

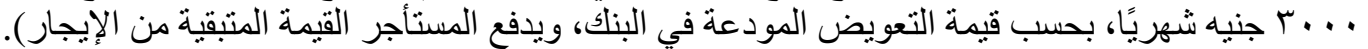

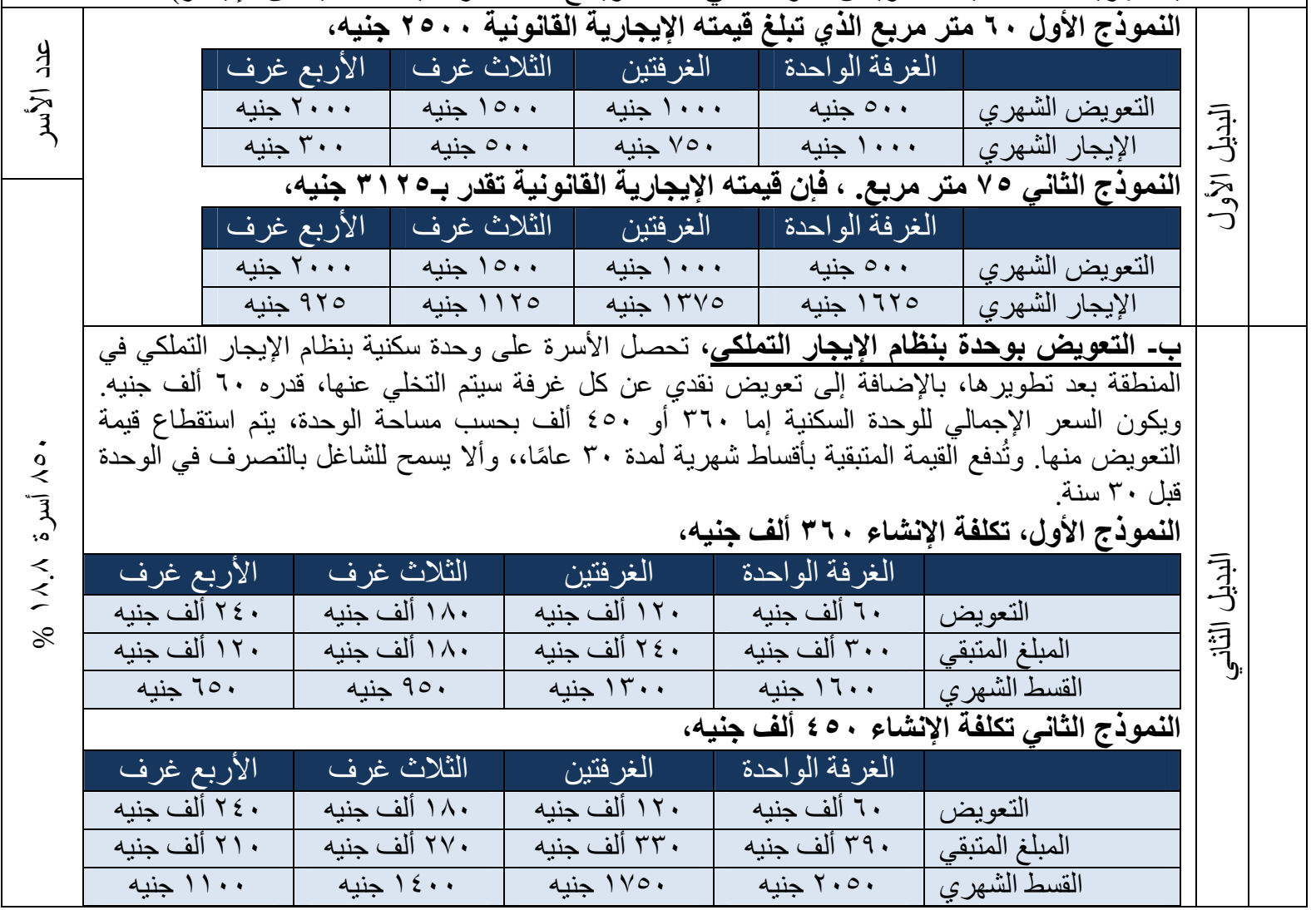




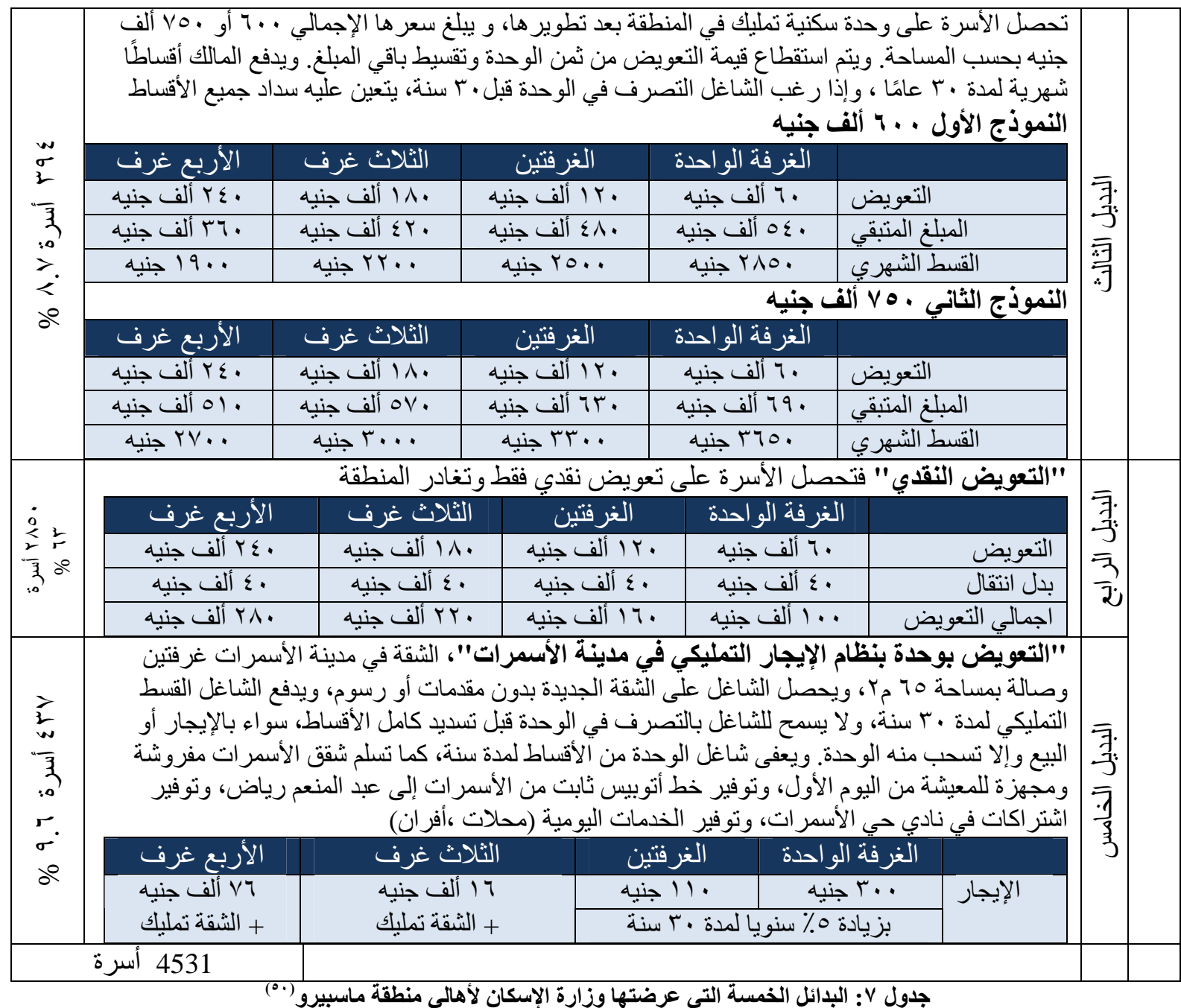

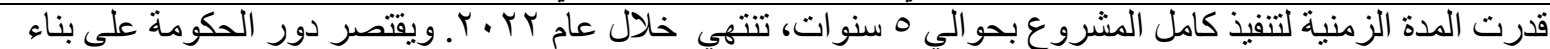

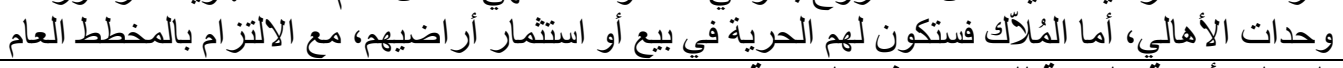

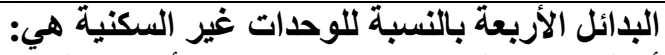

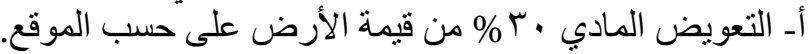

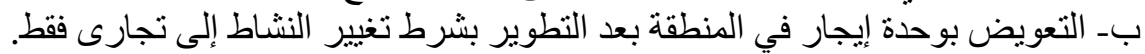

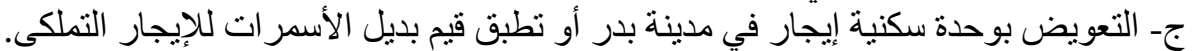

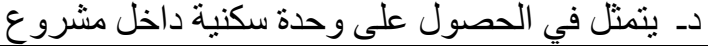

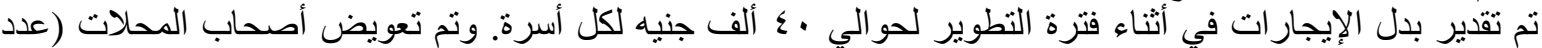

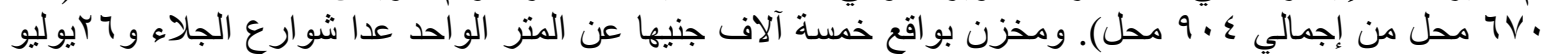

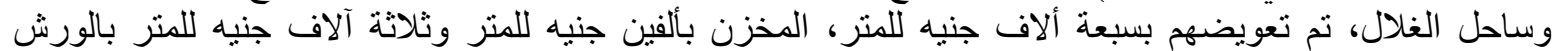

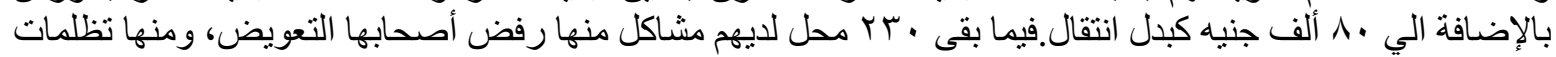

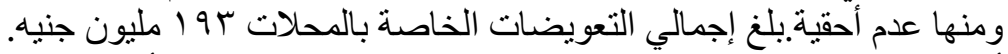

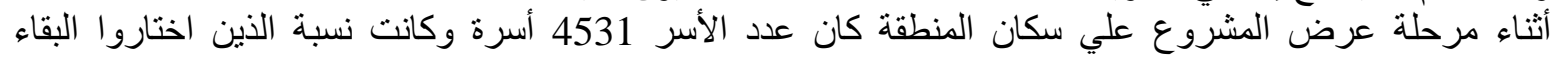
بماسبيرو ع. V Y \% من إجمالي السكان و ونسبة الذين اختاروا الحصول علي تعويض مباشر ومغادرة ماسبيرو كانت

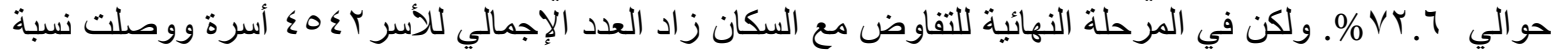

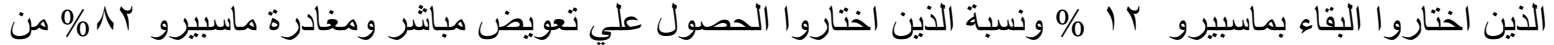

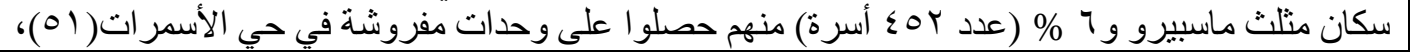


ع · r • ج . انتقادات المشروع:

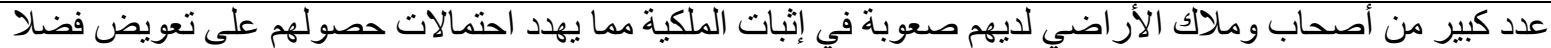

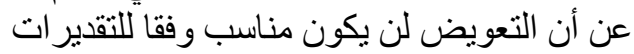

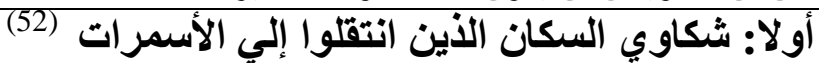

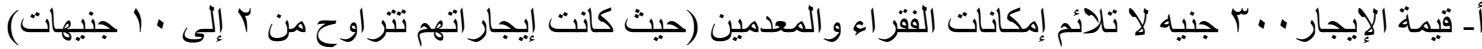

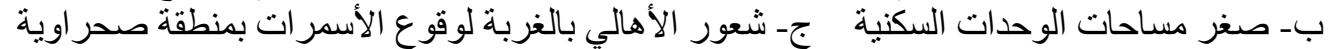

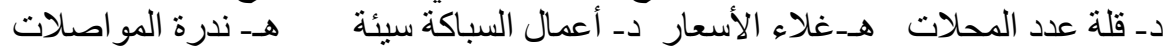

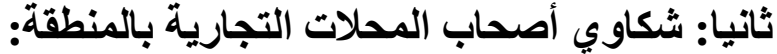

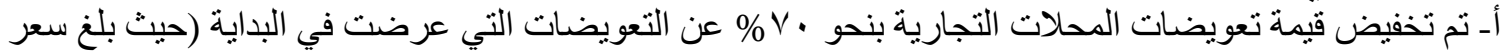

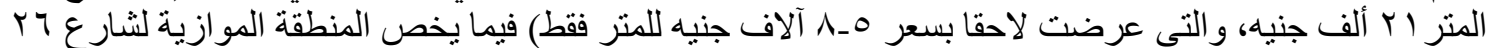

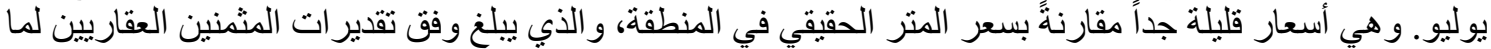

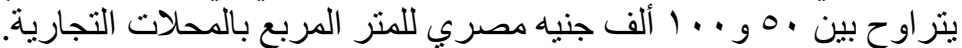

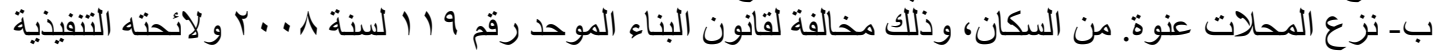

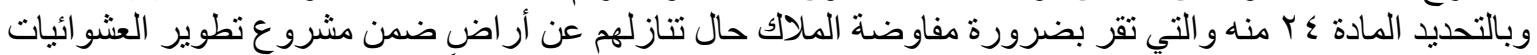

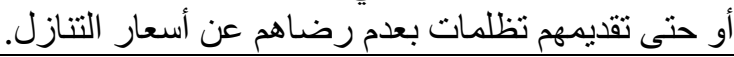

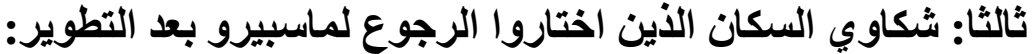
أـ طول المدة الزمنية لتطوير المنطقة(س سنوات على الأقل) وطالبو ا بمدة زمنية محددة للعودة إلى المئل المنطقة.

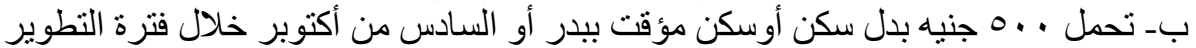

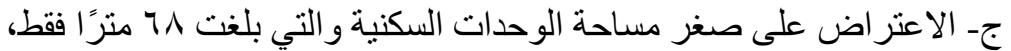

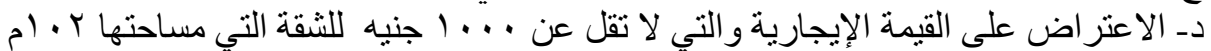

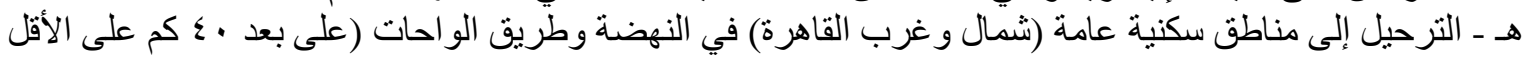

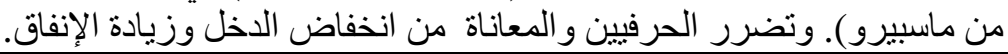

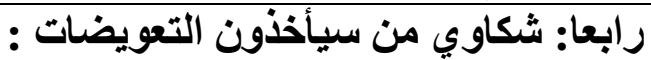

تقدير ات لجان التقييم كانت غير مقبولة (قدر متر السكن بما لا يزيد على ع آلاف جنيه في حين أن تقييمات أخرى في

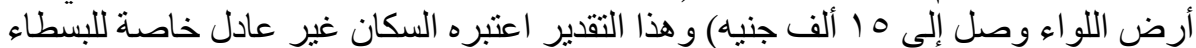

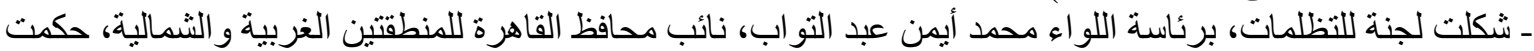

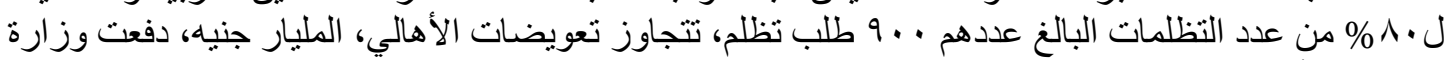
الإسكان للأهالي منها من . . 7 مليون جنيه

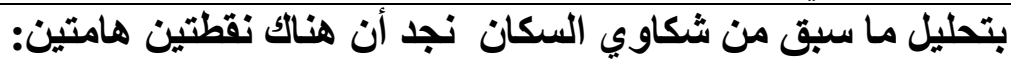

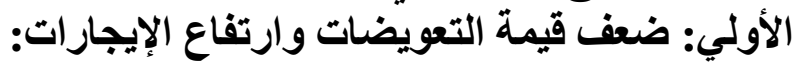

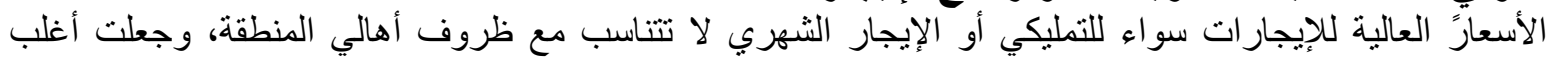

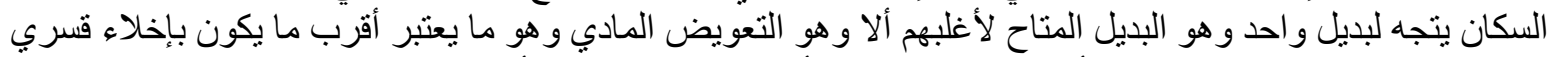

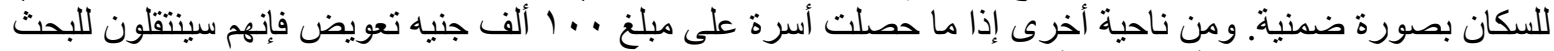

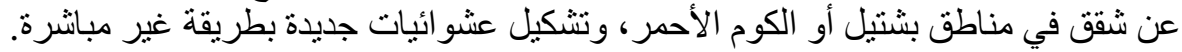

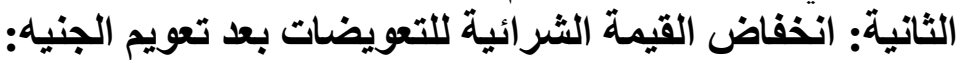

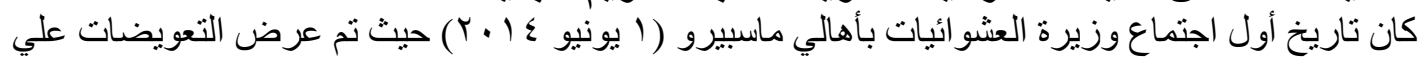

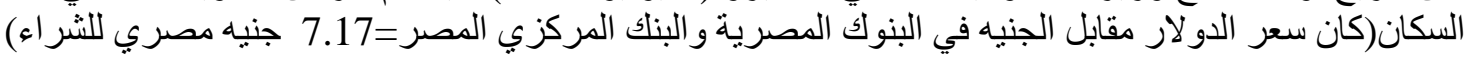

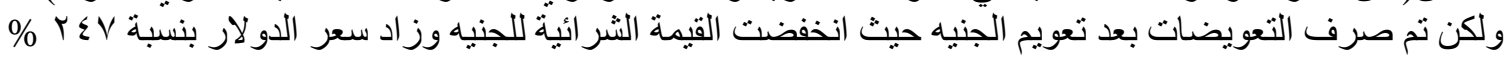

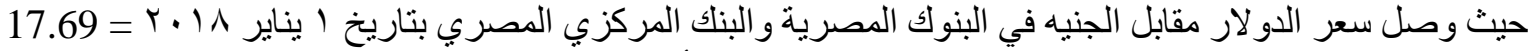

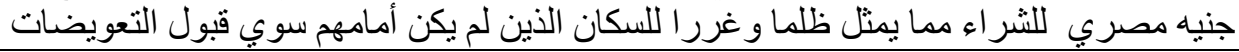

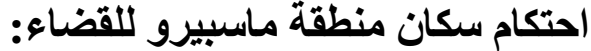

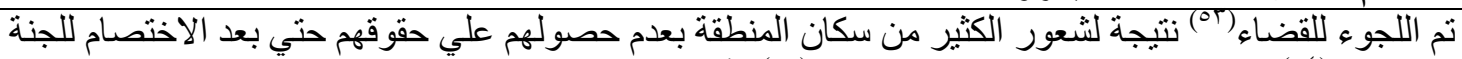

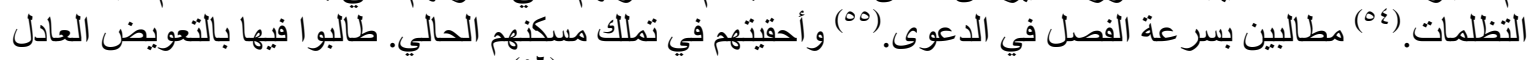

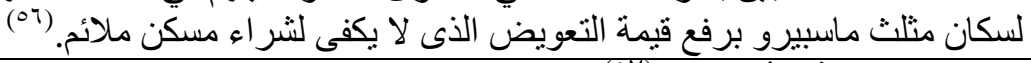

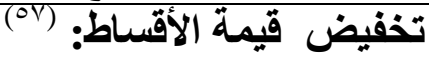
تمت المو افقة علي تخفيض قيمة الأقساط(01) و الحفاظ علي القيمة الإجمالية لسعر الثقة داخل المنطقة، وخفض القيم

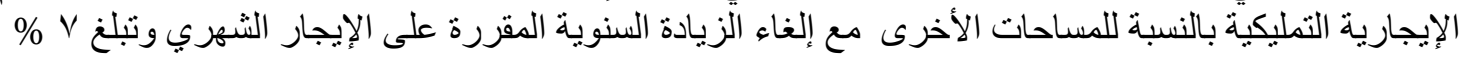




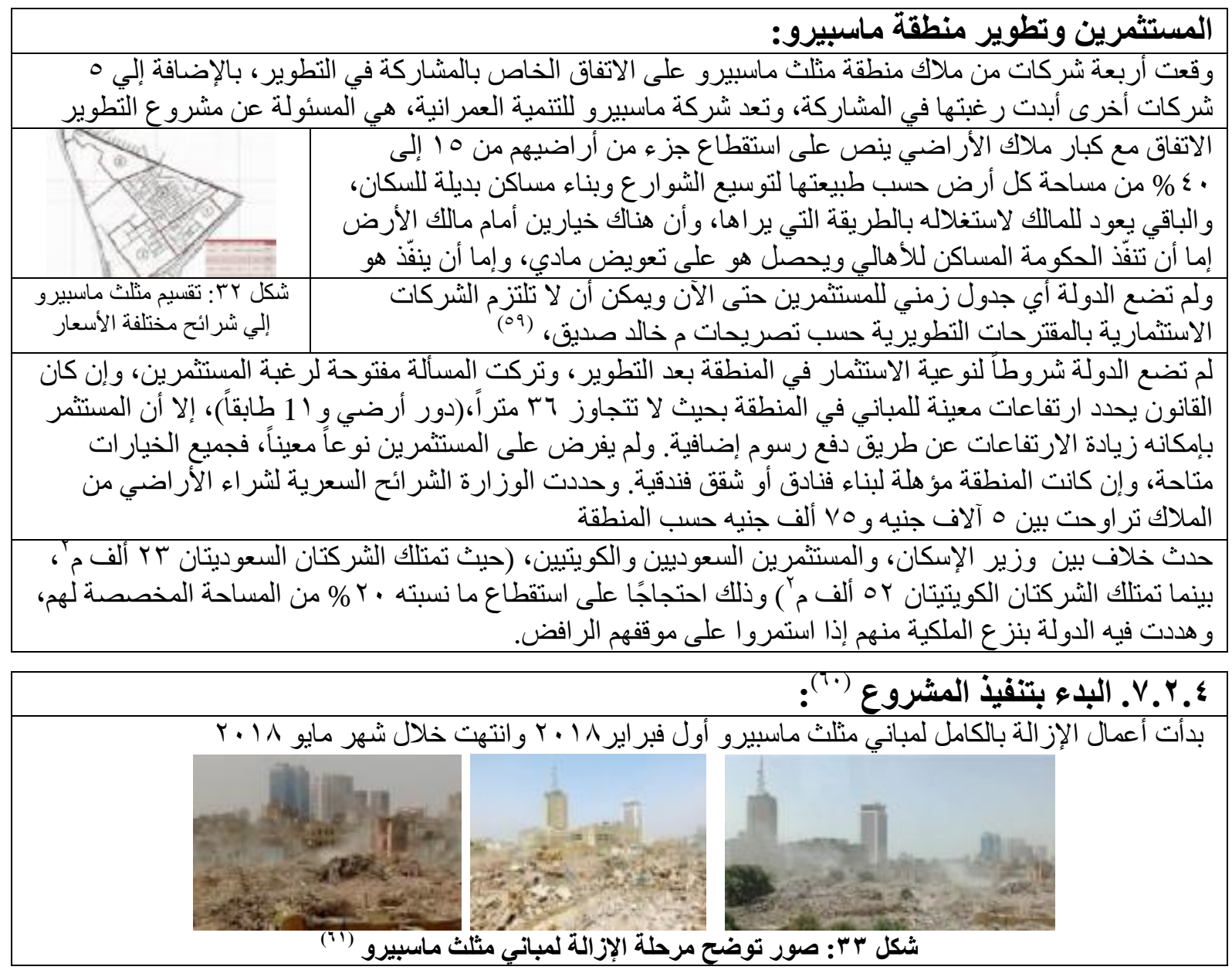

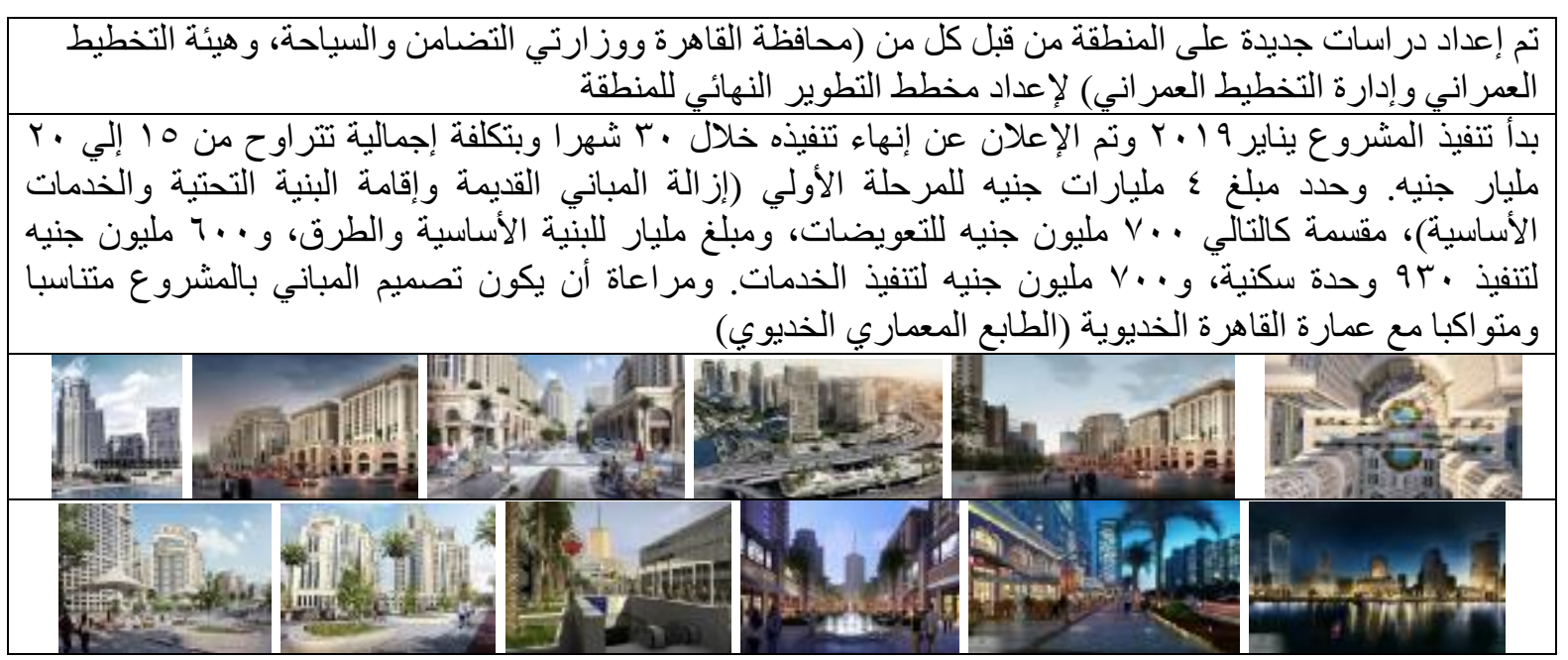




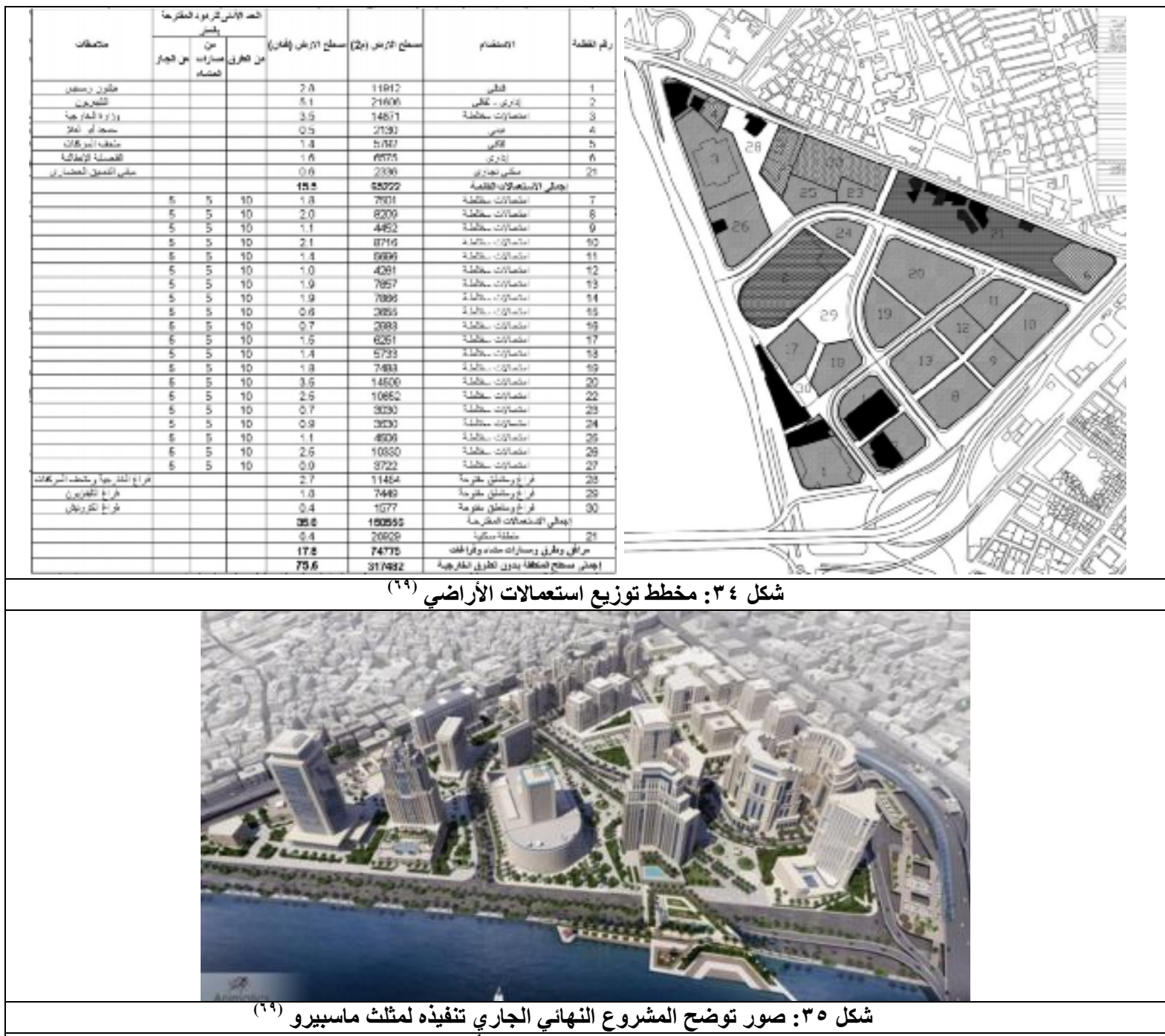

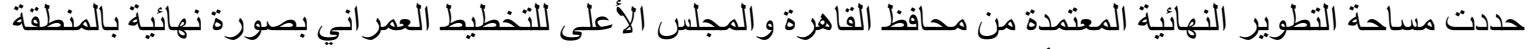

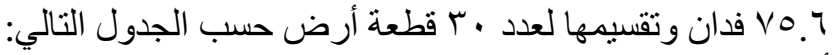

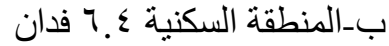

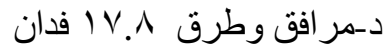

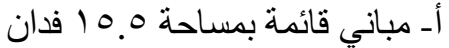

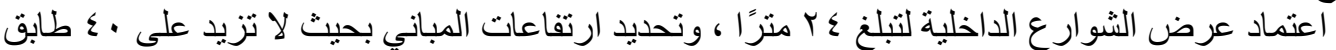

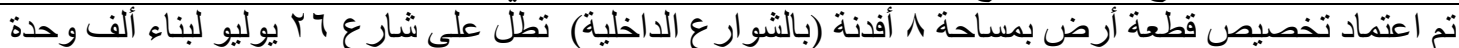

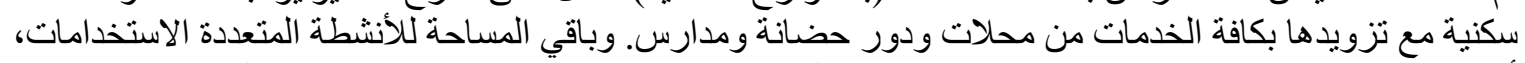

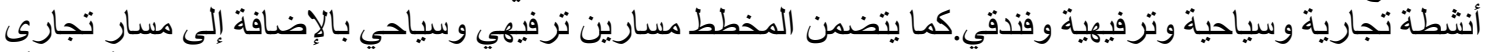

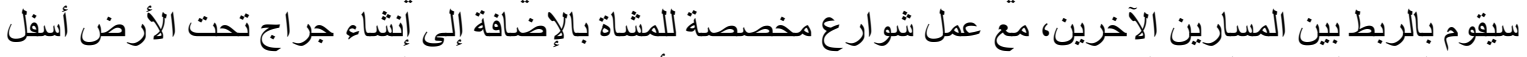

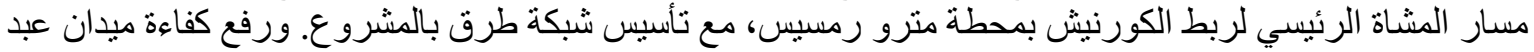

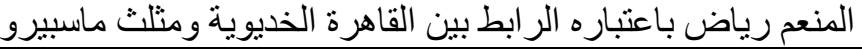

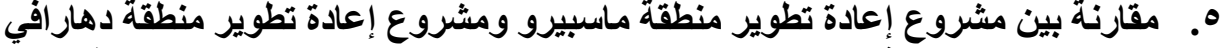

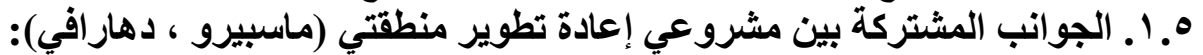

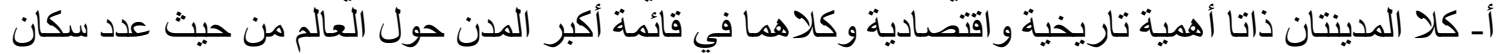

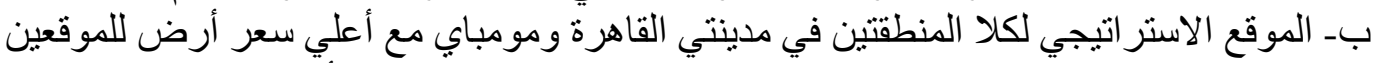

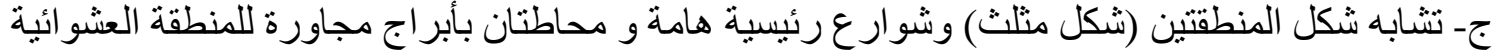

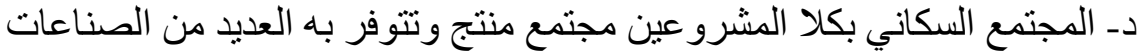

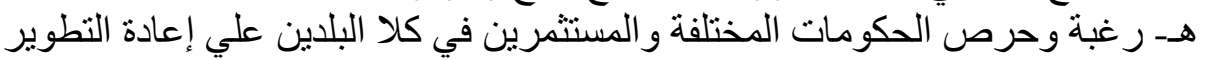

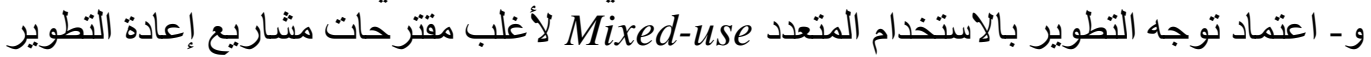
ز - الاتجاه إلي اختيار التكثيف الر اسي High rise Building و اقتر اح زيادة معامل البناء (FAR) 
๑. •. دراسة مقارنة للجوانب المختلفة بين المشروعين:

\begin{tabular}{|c|c|c|c|}
\hline منطقة دهارافي & منطقة ماسبيرو & وجه المقارنة & p \\
\hline 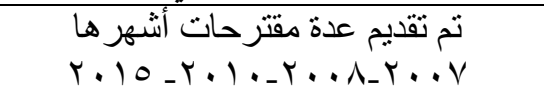 & 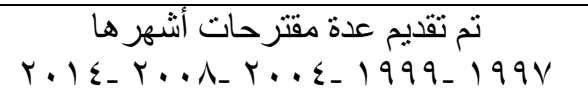 & المقترحات المختلفة & 1 \\
\hline تم اعتماد التكثيف الر أسي وزيادة معامل & تم اعتماده في المقترحات الاولية للمسابقة & $\begin{array}{l}\text { زيادة معامل البناء } \\
\text { FAR }\end{array}$ & $r$ \\
\hline تم عملها في عام r I. T & تم عملها في عام ع ب. T & عقد مسابقة عالمية & $r$ \\
\hline 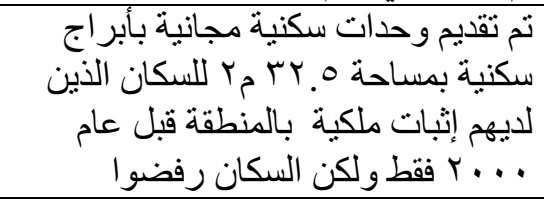 & 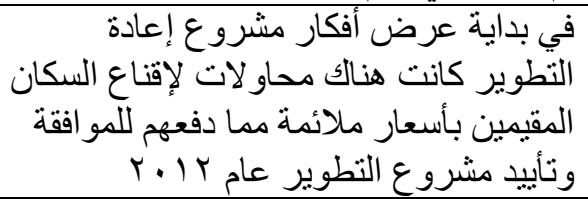 & 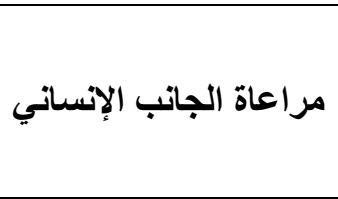 & $\varepsilon$ \\
\hline 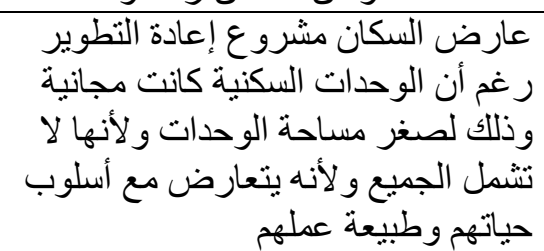 & 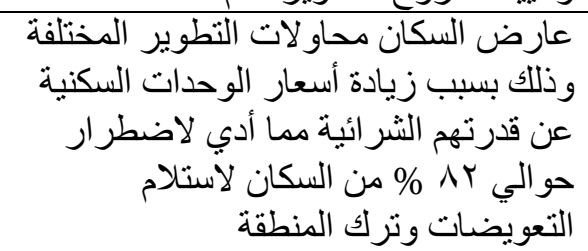 & مشروع إعادة التطوير موقف & 0 \\
\hline 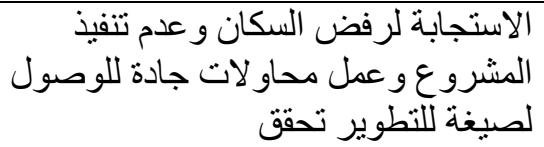 & 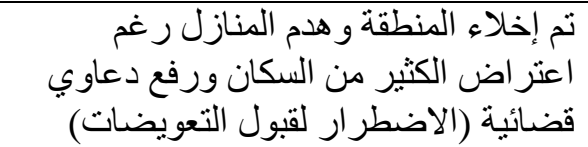 & موقف الحكومة & 7 \\
\hline تم تقديم عدة مقترحات تشاركية أشُهر ها & 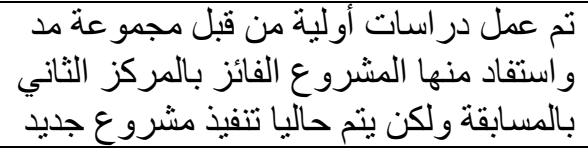 & التصميم التشاركي & $V$ \\
\hline 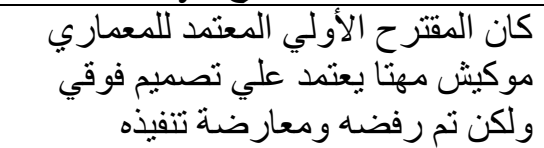 & 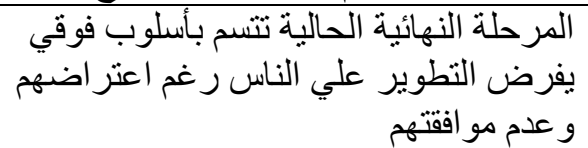 & 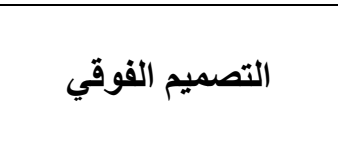 & $\Lambda$ \\
\hline
\end{tabular}

جدول ^: مقارنة بين مشروع إعادة تطوير منطقة ماسبيرو ومشروع إعادة تطوير منطقة دهار افي (المصدر: الباحث)

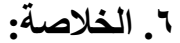

تعثرت أغلب المحاو لات التطويرية للمنطقتين الدر اسيتين بسبب عدم مر اعاة الجانب الإنساني مما أدي لخسائر لكل من:

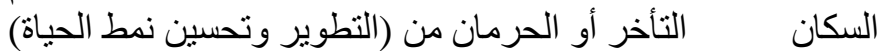

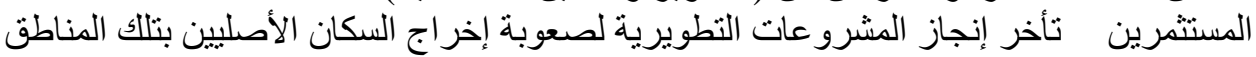

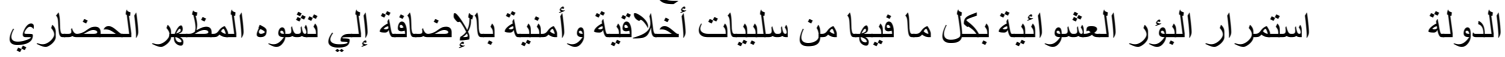

بلاحظ أن الدر اسات و الأفكار التطويرية والمسابقات لكلا المشروعين كانتا في مرحلة زمنية متقاربة حيث بدأت

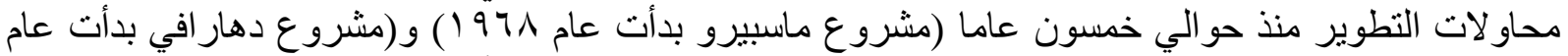

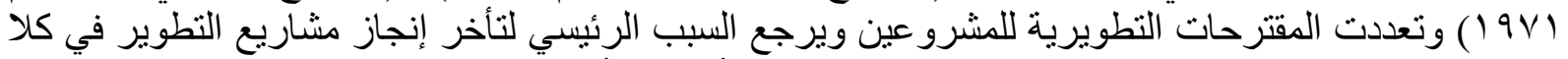

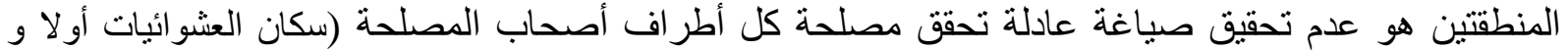
المطورين والدولة) في آن واحد. فالمدة الزمنية الطويلة التي استغرقتها دراسات ومحاولات التئ التطوير كلا

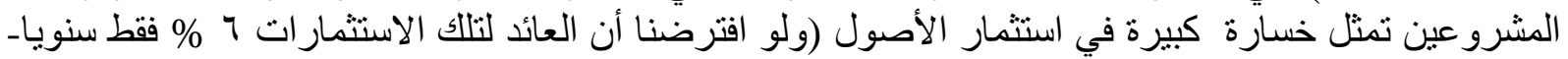

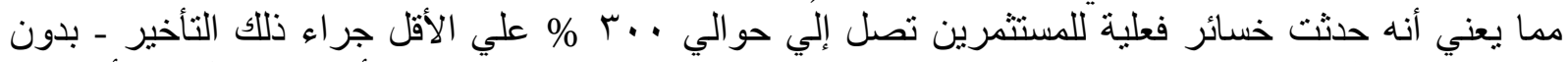

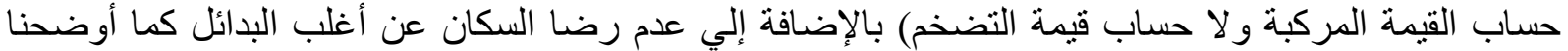

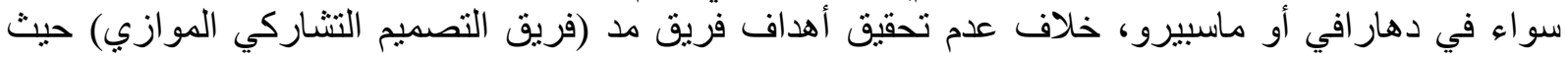

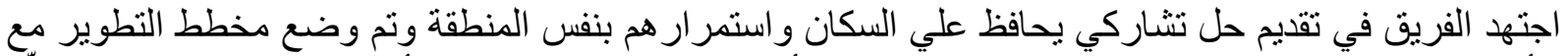

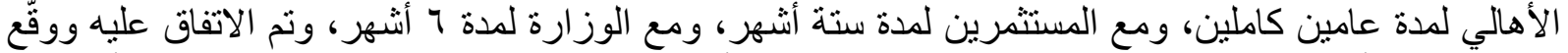

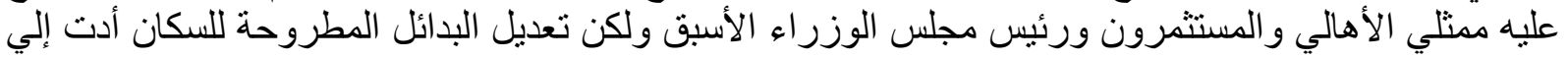

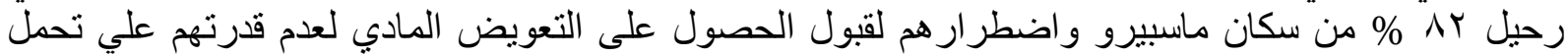

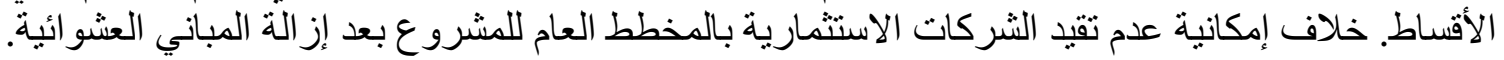




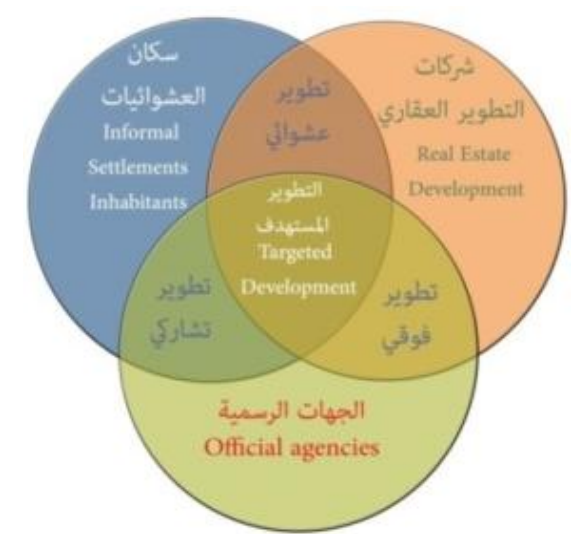

شكل بr: تصور للعلاقة بين السكان والمطورين والجهات الرسمية والتطوير المستهرف (المصدر: الباحث)

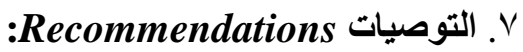

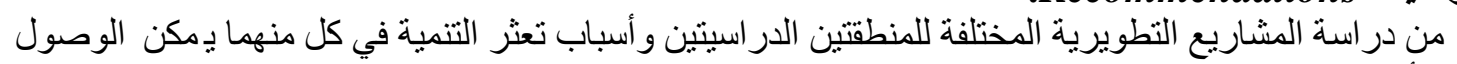

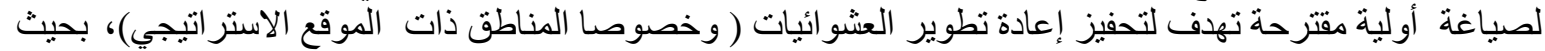
تكون الصباغة عادلة تحقق الاستفادة لجميع أصحاب المصلحة.

يجب مراعاة النقاط الآتية عند إعداد مشروع تطوير منطقة عشوائية:

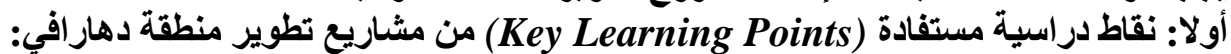

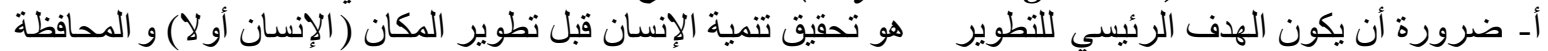

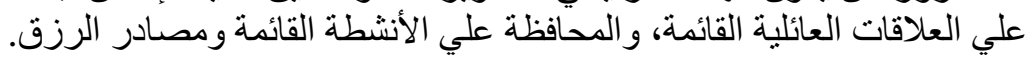

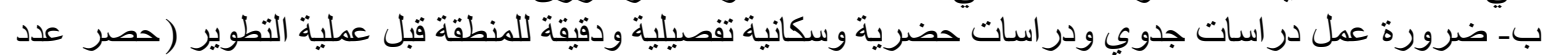

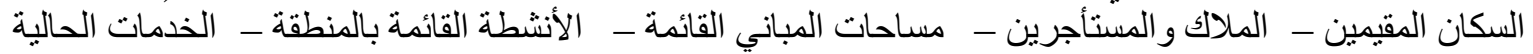
القائمة) و عمل قاعدة بيانات محدثة بـ نظام معلومات جغر افي Geographic Information System (GIS) يستو عب التطوير جميع سكان المنطقة.

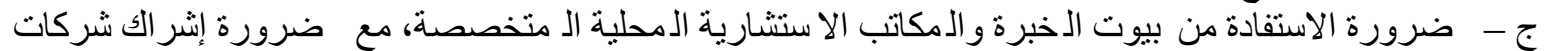
استشارية ذات خبرات عالمية - خصوصا في في المشاريع الحضرية الكبرى (MUPS). مع إمكانية عمل مسابقة لكل

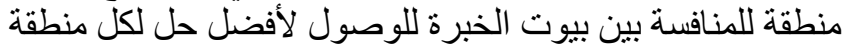

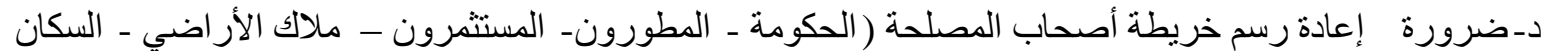

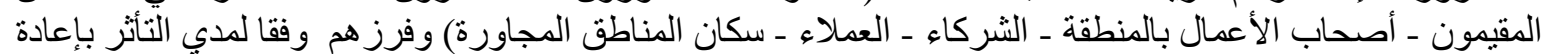

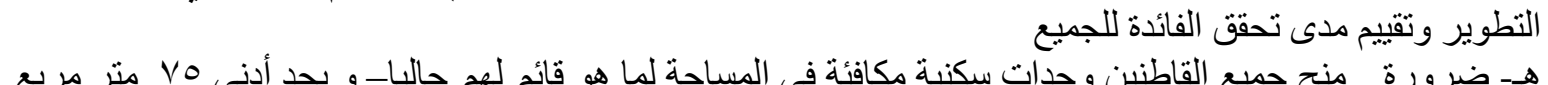

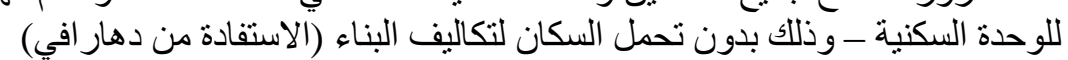

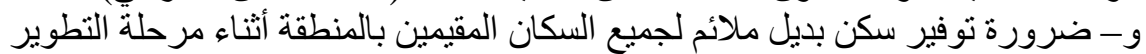

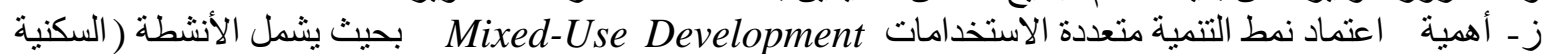

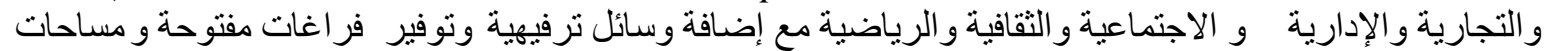

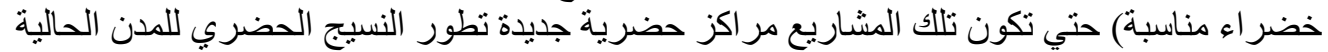

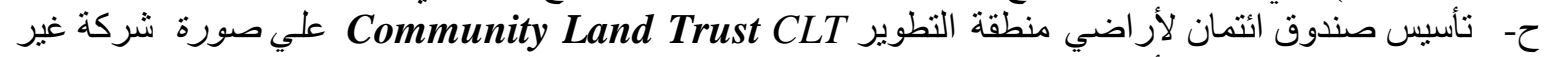

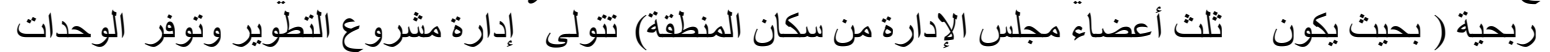

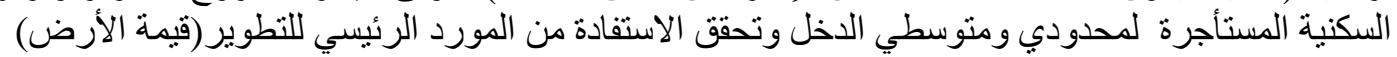

ثانيا: نقاط دراسية مستفادة (Key Learning Points) من مشاريع تطوير منطقة ماسبيرو:

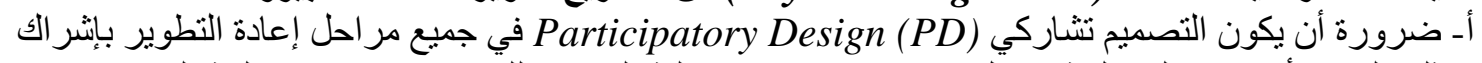

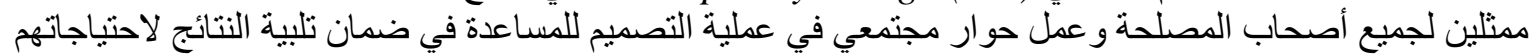

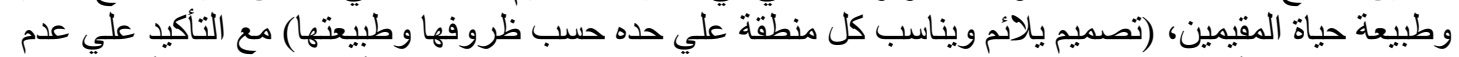

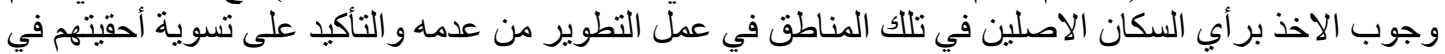

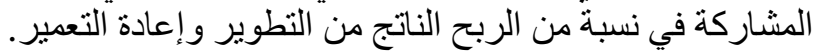
بـ ضرورة مر اعاة الضو ابط الآتية للتكثيف الر أسي لمو اقع التطوير : 


$$
\begin{aligned}
& \text { نحو تنمية مستدامة متعددة الاستخدامات ذات بعد إنساني للمناطق العشو ائية بمر اكز الدن دراسة مقارنة لمشاريع إعادة تطوير منطقتي (دهار افي، مومباي }
\end{aligned}
$$

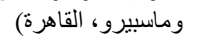

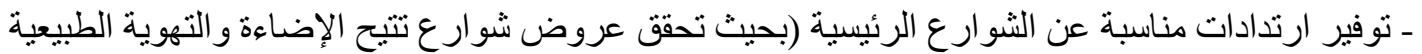

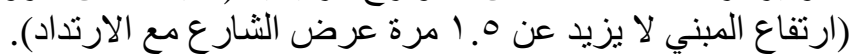

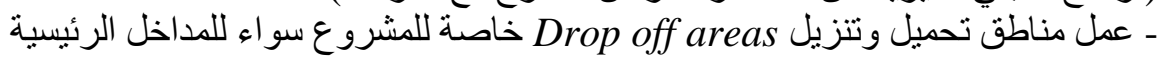

$$
\begin{aligned}
& \text { - توفير مو اقف سيار ات بالأدو ار السفلية بالإضافة إلي مو اقف سطحية. }
\end{aligned}
$$

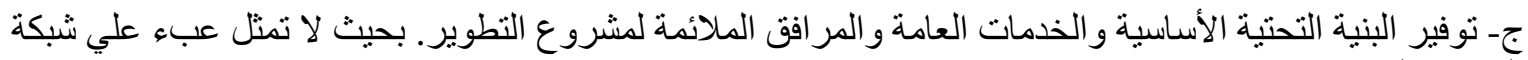

$$
\begin{aligned}
& \text { المثر افق القائمة } \\
& \text { ثالثا: نقاط يجب مراعاتها عند اعتماد مشروع التطوير: }
\end{aligned}
$$

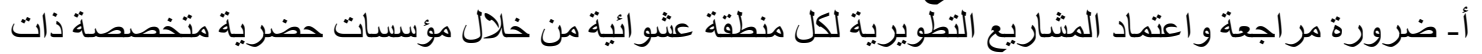

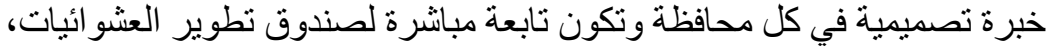

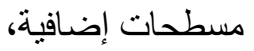

$$
\begin{aligned}
& \text { ج- التأكيد علي ضرورة إلافة الاتفادة من المبادر ات الدولية والجهات المانحة. }
\end{aligned}
$$

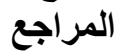

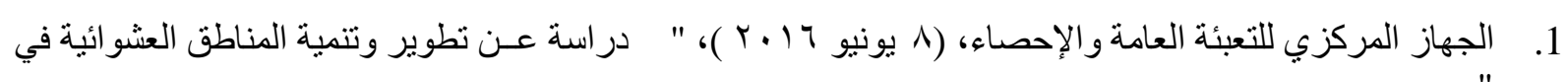

weirdcorner.com/wp-content/uploads/2011/02/Egypt_garbage_city.jpg منطقة الدويقة) ملزبة)

مدينة القمامة (الزبالين)، منشية ناصر، القاهرة، مصر Garbage City Manshiyat Naser, Cairo, Egypt https://www.reddit.com/r/UrbanHell/comments/8ryg8f/garbage_city_manshiyat_naser_cairo_

3.

Www.capmas.gov.eg

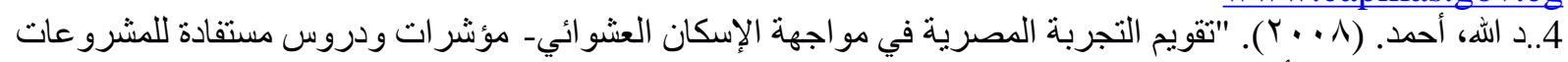

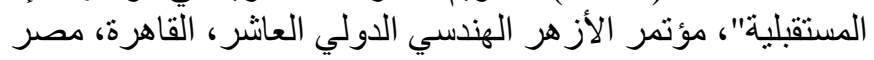

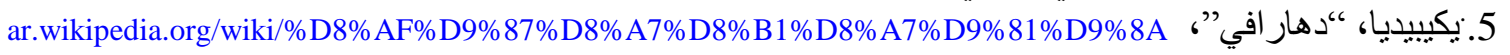

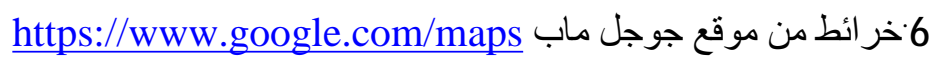

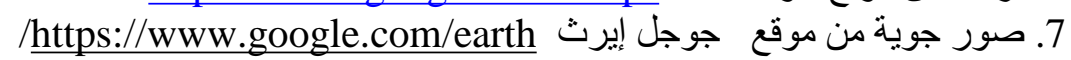

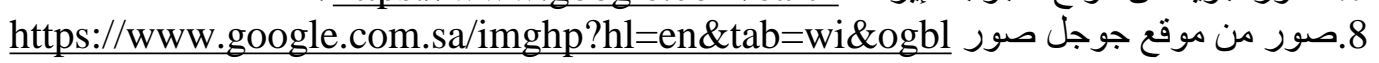

9. UDP International, (2015), "Naya Dharavi Nurture a community vision to plan a sustainablefuture", static1.squarespace.com/static/5611ed20e4b0e5d9aa3b2754/t/59a507879f7456e682663 ce1/1503987696879/Dharavi.compressed.pdf

10. Mumbai Population 2019, (5-12-2019),worldpopulationreview.com/worldcities/mumbai-population/

11. قيمة 1000روبيه هندي = 14.38 دو لار أمريكي ـ الدو لار الأمريكي = سه.بی روبية هندية (2019-06-10) /https://www.worldforexrates.com/ar/inr/usd/1000-exchange-rate

12. "Learning from Dharavi Redevelopment Project".(2015). Mumbai, India https://issuu.com/abrahamhalim/docs/20160426_epc_draft__1

13. UDP International, (2015), "Naya Dharavi Nurture a community vision to plan a sustainable future",

static1.squarespace.com/static/5611ed20e4b0e5d9aa3b2754/t/59a507879f7456e682663ce1

/1503987696879/Dharavi.compressed.pdf

14. Wikipedia, Dharavi, en.wikipedia.org/wiki/Dharavi

15. Rajadhyaksha, Niranjan. (04 Oct 2007). "Dharavi’s makeover man", www.livemint.com/Leisure/b67oGfRdzjmryoRk8PDkGO/Dharavi8217s-makeoverman.html 
16. Hinduja, Udit, (23 Feb 2011). "Dharavi - Beyond The Slum", Notenoughgood.Com/2011/02/Dharavi/

17. M M Project Consultants Pvt. Ltd. "Dharavi Slum Redevelopment". Www.Mmpcpl.Com/Projects-M-M-Project-Consultants-Pv

18. "Brain Behind Dharavi Redevelopment Project In The Dock" Www.Dnaindia.Com/Mumbai/Report-Brain-Behind-Dharavi-Redevelopment-ProjectIn-The-Dock-1688385

19. "7-Year-Itch For Dharavi Redevelopment Project". (24 Apr, 2012).

Www.Mid-Day.Com/Articles/7-Year-Itch-For-Dharavi-Redevelopment-Project/159640

20. Gandhi, Mayank, Wood ,Antony. (2010). "Mumbai Conference Report". Https://Store.Ctbuh.Org/Conference-Publications/82-2010-Mumbai-ConferenceReport.Htm

21. Mehta, Mukesh, (2010), "Dharavi Redevelopment Project”, Remaking Sustainable Cities In The Vertical Age Conference, India Www.Ctbuh.Org/Linkclick.Aspx?Fileticket=Ncnpcnoalpk\%3D\&Tabid=1421\&Langua ge=En-US

22. Kamla Raheja Vidyanidhi Institute For Architecture, "Dharavi Redevelopment Plan, Concerns And Critique

23. Whiting, Dominic. (June 8, 2008). "Dharavi Dwellers Face Ruin In Development Blitz In.Reuters.Com/Article/Idinindia-33958520080608

24 Kamla Raheja Vidyanidhi Institute For Architecture, “Dharavi Redevelopment Plan, Concerns And Critique

25. Foster And Partners. (2008). "Dharavi Masterplan". Www.Fosterandpartners.Com/Projects/Dharavi-Masterplan/

26 Dharavi Hok Book-Final Dharavievolution.Typepad.Com/Files/Hok_Dharavi_BookFinal-Lowres-1.Pdf

27 (As+Gg ) Adrian Smith+ Gordon Gill. (2008). "Mumbai Master Plan" smithgill.com/media/pdfs/mumbai_master_plan_for_web_2.pdf 28.. Proposed-dharavi-redevelopment-by-hafeez-contractor-architects8 29. 0020 Urban Design Research Institute, Mumbai, India. www.udri.org/ 30. Reinventing Dharavi, Awards . www.reinventingdharavi.org/awards.php

$$
\begin{aligned}
& 31 \text { • تقبيم عضو لجنة تحكيم المنافسة (سايروسجوزدر)، رئيس مجلس الإدارة و المدير العام ، عضو في لجنة الحفاظ }
\end{aligned}
$$

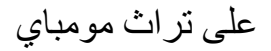

$$
\begin{aligned}
& 32 \text {.تحليل المهندس (شيريش باتل) ، مؤسس شركة شيريش باتل وشركاه عن المشروع الفائز بالمسابقة }
\end{aligned}
$$

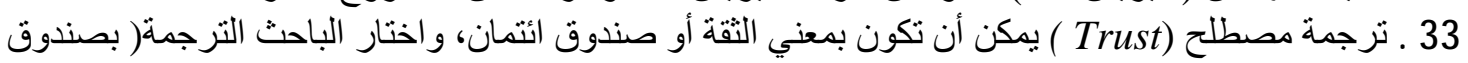

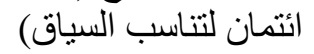

34. (September 16, 2017). "Community land trust model best suited to reinvent Dharavi “ www.thehindu.com/news/cities/mumbai/community-land-trust-model-best-suited-toreinvent-dharavi/article19700938.ece

35. Planning Principles For Redevelopment Of Dharavi www.plural.org.in/redevelopment-of-dharavi

36. Carr, Carlin. (18 Feb 2015). "The best idea to redevelop Dharavi slum? Scrap the plans and start again"

www.theguardian.com/cities/2015/feb/18/best-ideas-redevelop-dharavi-slumdevelopers-india

37. Zaazaa, Ahmed, (December 2015), "Maspero parallel participatory project", by Madd Platform, Egyptian Ministry of State for Urban Renewal and Informal Settlements. issuudownload.tiny-tools.com/print.php?doc_id=160208133220-

b7d890b41eda098fceb5c4b0b2b4871

38عزع، أحمد و آخرون. (29 يوليو 1 • ب)، موقع مدي مصر ، "مثلث ماسبيرو. هل يحظى السكان بنهاية سعيدة؟"، www.madamasr.com 
39. Vision of Cairo 2050, h ps://cairofrombelow.files.wordpress.com/2011/08/cairo2050-vision-v-2009-gopp-12-mb.pdf

40. مكتب خدمة المستثمرين- محافظة القاهرة

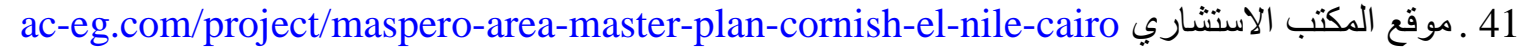

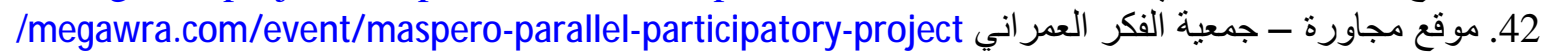

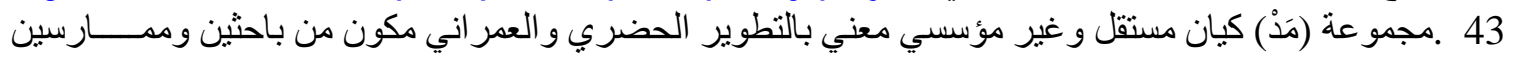

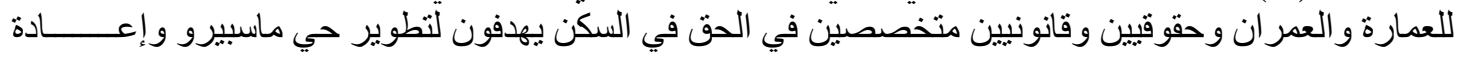

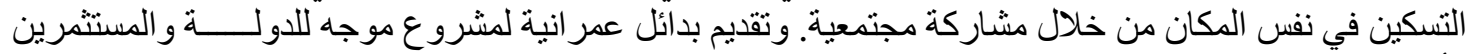

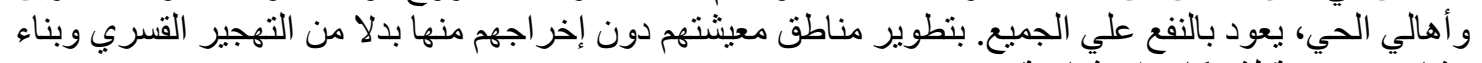
مشاريع ضخمة لثركات استثمارية

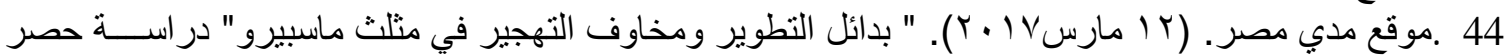

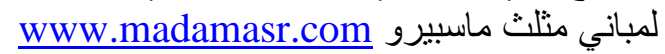

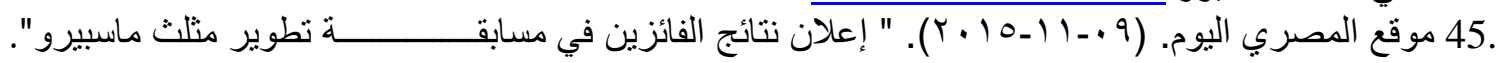
www.almasryalyoum.com/news/details/840809

46. Brooker, Grant. (09 November 2015). “Foster + Partners wins Maspero Triangle District Masterplan Design Competition”. www.fosterandpartners.com/news/archive/2015/11/foster-partners-wins-masperotriangle-district-^${ }^{\wedge}$ masterplan-design-competition/

47 ـموقع مدي مصر .( 12 نوفمبر 10 • ب). " شركة هندسية تكثف عن مخططات تطوير منلث ماسبيرو المتنازع

(48) https:// www.fosterandpartners.com/ عليه" عنسية

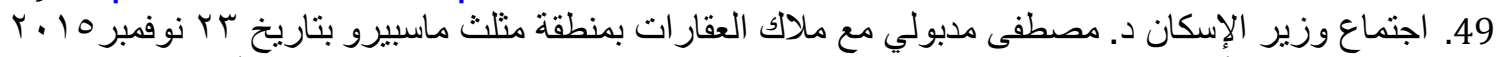

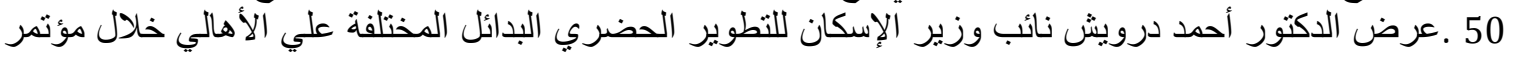

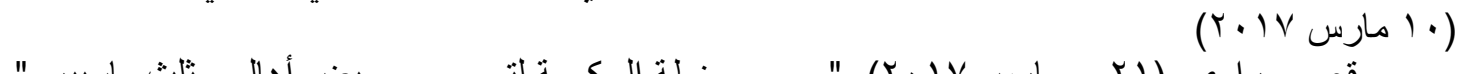

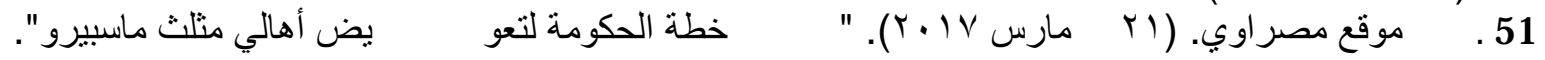
www.masrawy.com

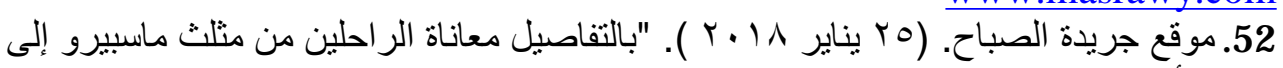

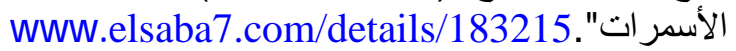

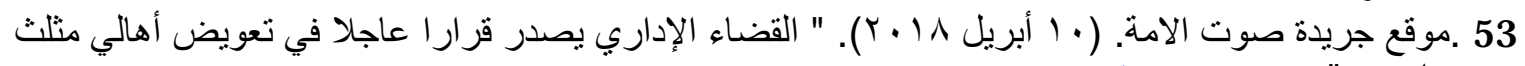

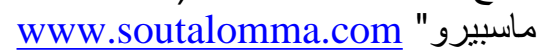

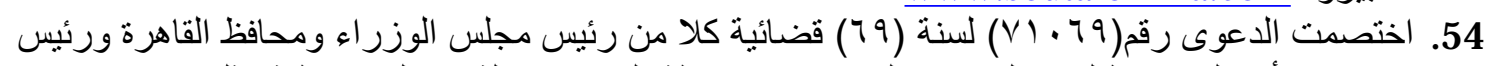

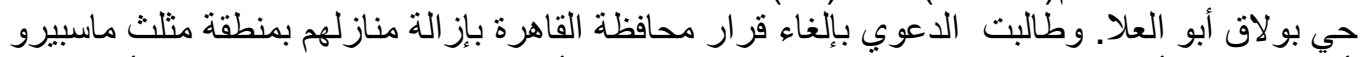

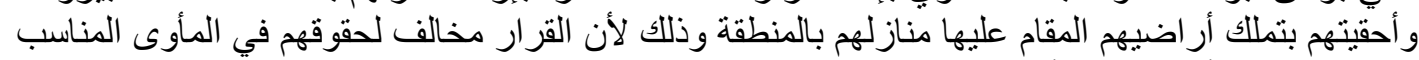

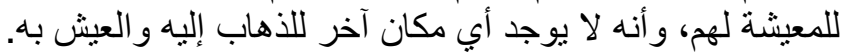

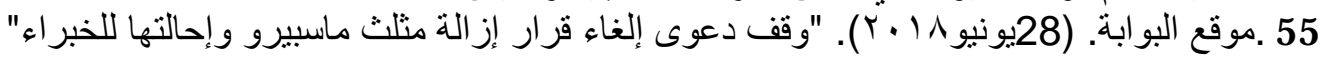
www.albawabhnews.com/3166793

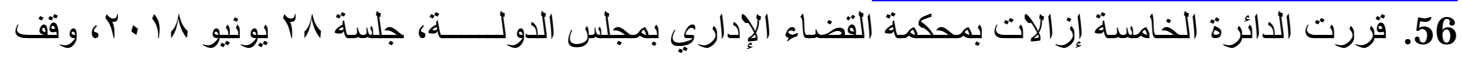

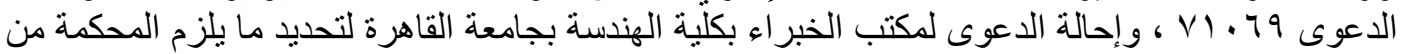

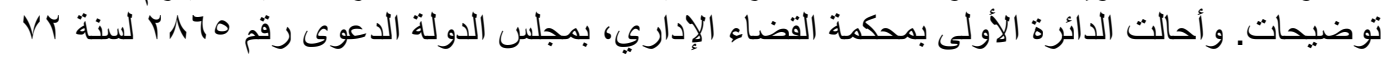

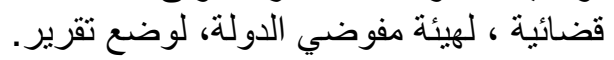

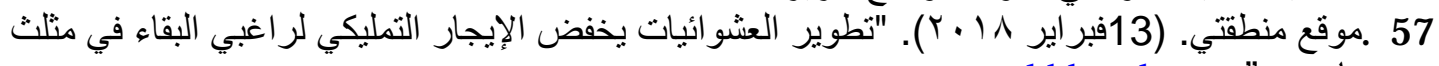

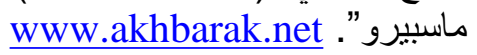

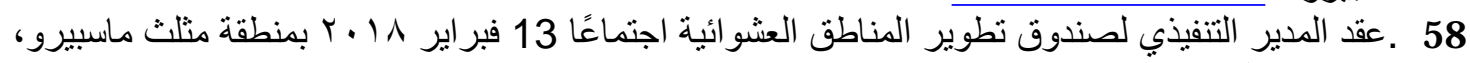

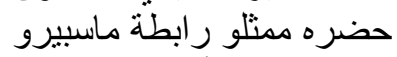

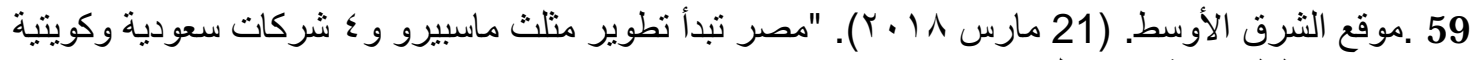

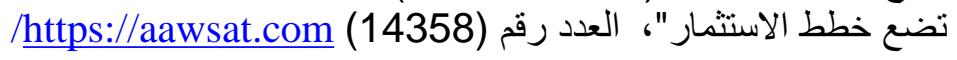

